ORNL/CON-492

\title{
AN EVALUATION OF STATE ENERGY PROGRAM ACCOMPLISHMENTS: 2002 PROGRAM YEAR
}

\author{
Martin Schweitzer \\ Bruce E. Tonn
}




\section{DOCUMENT AVAILABILITY}

Reports produced after January 1, 1996, are generally available free via the U.S. Department of Energy (DOE) Information Bridge.

Web site http://www.osti.gov/bridge

Reports produced before January 1, 1996, may be purchased by members of the public from the following source.

National Technical Information Service

5285 Port Royal Road

Springfield, VA 22161

Telephone 703-605-6000 (1-800-553-6847)

TDD 703-487-4639

Fax 703-605-6900

E-mail info@ntis.fedworld.gov

Web site http://www.ntis.gov/support/ordernowabout.htm

Reports are available to DOE employees, DOE contractors, Energy Technology Data

Exchange (ETDE) representatives, and International Nuclear Information System (INIS)

representatives from the following source.

Office of Scientific and Technical Information

P.O. Box 62

Oak Ridge, TN 37831

Telephone 865-576-8401

Fax 865-576-5728

E-mail reports@adonis.osti.gov

Web site http://www.osti.gov/contact.html

This report was prepared as an account of work sponsored by an agency of the United States Government. Neither the United States Government nor any agency thereof, nor any of their employees, makes any warranty, express or implied, or assumes any legal liability or responsibility for the accuracy, completeness, or usefulness of any information, apparatus, product, or process disclosed, or represents that its use would not infringe privately owned rights. Reference herein to any specific commercial product, process, or service by trade name, trademark, manufacturer, or otherwise, does not necessarily constitute or imply its endorsement, recommendation, or favoring by the United States Government or any agency thereof. The views and opinions of authors expressed herein do not necessarily state or reflect those of the United States Government or any agency thereof. 


\title{
AN EVALUATION OF \\ STATE ENERGY PROGRAM ACCOMPLISHMENTS: 2002 PROGRAM YEAR
}

\author{
Martin Schweitzer \\ Bruce E. Tonn
}

Date Published: June 2005

Prepared for

U.S. Department of Energy

Office of the Weatherization and Intergovernmental Program

Budget Activity Number WI 0402000

Prepared by

OAK RIDGE NATIONAL LABORATORY

Oak Ridge, Tennessee 37831

Managed by

UT-BATTELLE

for the

U.S. DEPARTMENT OF ENERGY

under contract DE-AC05-00OR22725 



\section{CONTENTS}

\section{Page}

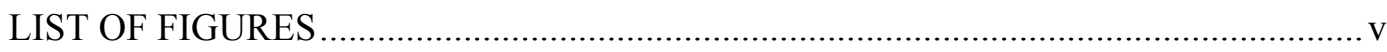

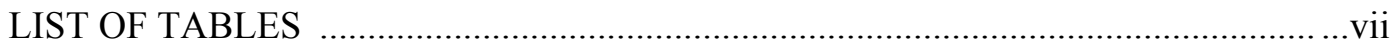

ABBREVIATIONS, ACRONYMS, AND INITIALISMS ............................................ix

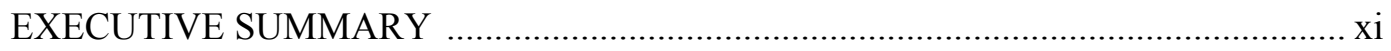

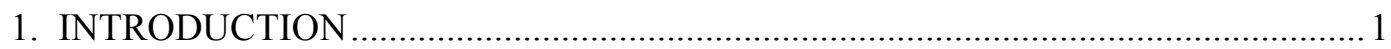

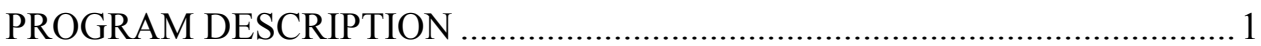

SEP PERFORMANCE METRICS ……................................................ 1

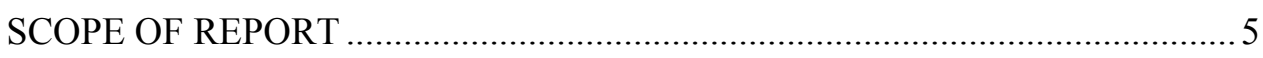

2. METHODS

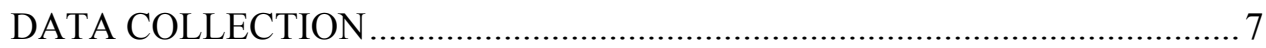

CALCULATING SAVINGS AND EMISSIONS REDUCTION ......................... 8

3. HOW TO INTERPRET THE ENERGY SAVINGS ESTIMATES........................... 13

FACTORS INFLUENCING UNCERTAINTY OF RESULTS.......................... 13

COMBINED EFFECTS OF UNCERTAINTY FACTORS .............................. 15

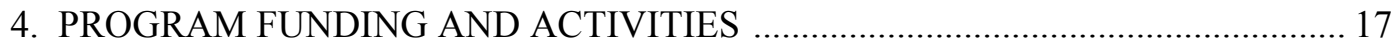

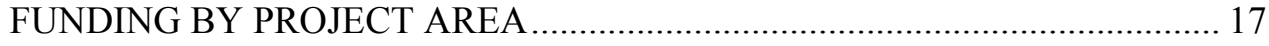

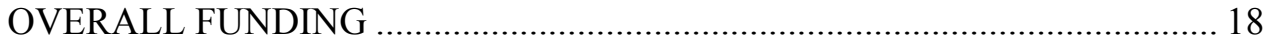

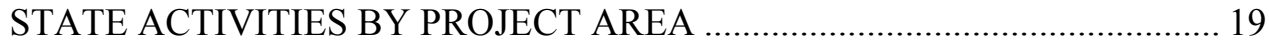

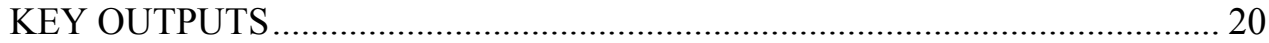

5. ENERGY AND COST SAVINGS AND EMISSIONS REDUCTION ........................ 23

SAVINGS AND EMISSIONS REDUCTIONS BY PROJECT AREA ............... 23

TOTAL SAVINGS AND EMISSIONS REDUCTIONS ................................... 25

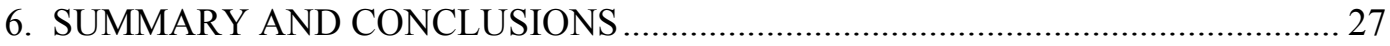

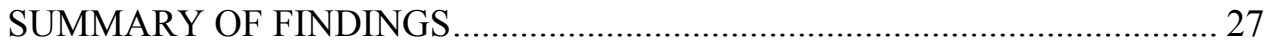

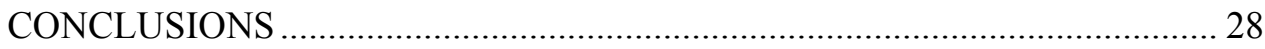

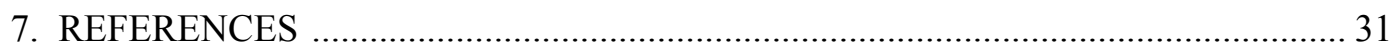

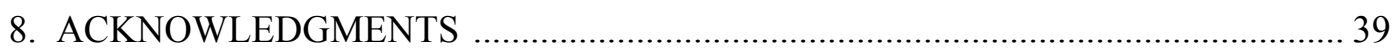

APPENDIX A — DEVELOPMENT OF ENERGY-SAVINGS COEFFICIENTS. ........ 41

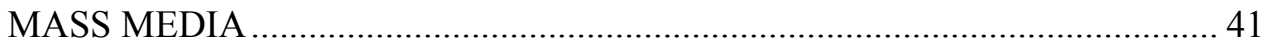

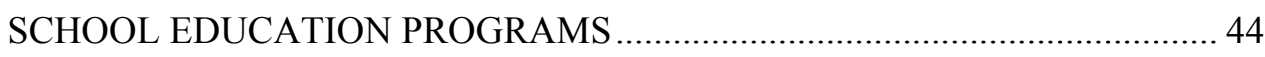

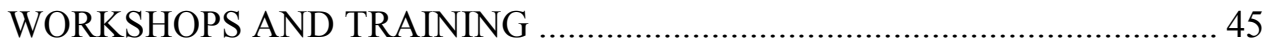

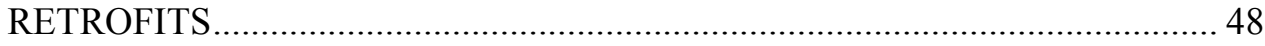

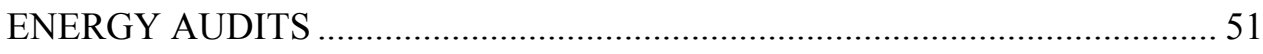

iii 
CONTENTS (continued)

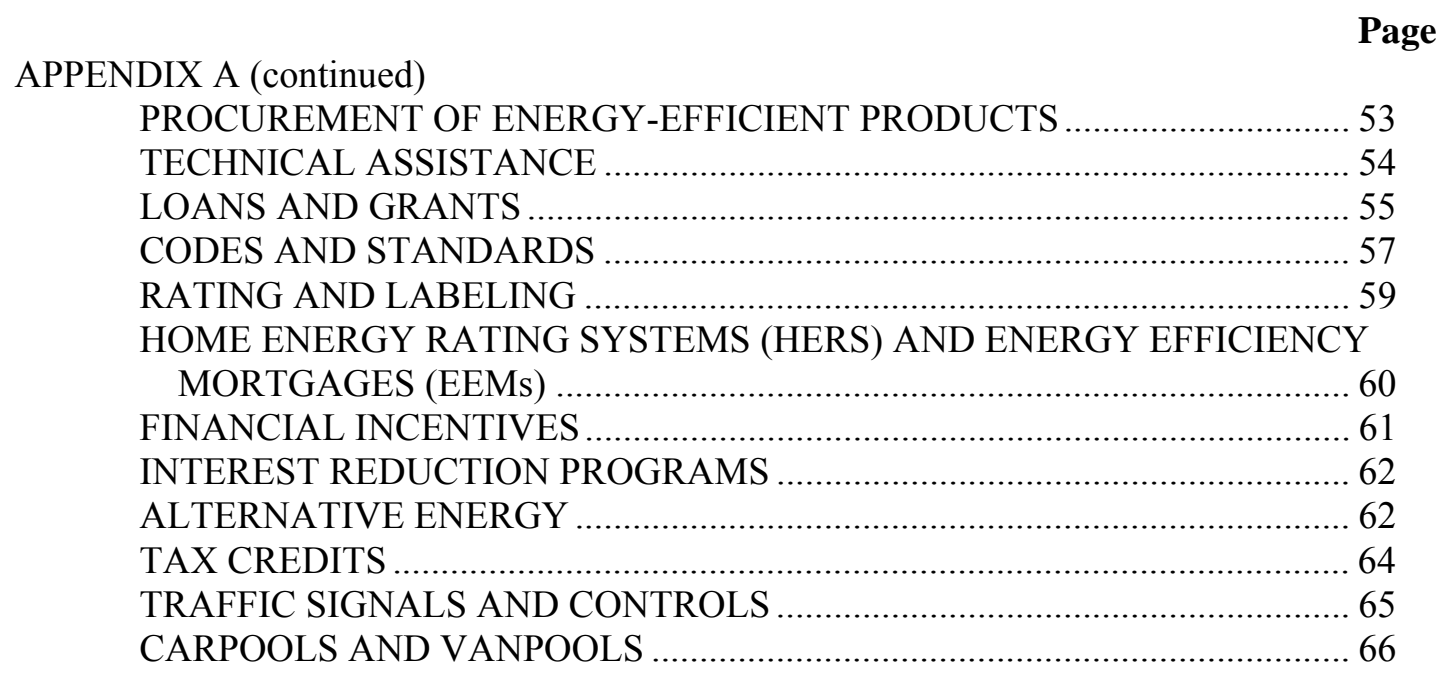

APPENDIX B — METHOD FOR CALCULATING EMISSIONS REDUCTIONS ...... 69 


\section{LIST OF FIGURES}

Figure

Page

ES.1. Estimated annual nationwide energy savings by project area ............................. xiv

ES.2. Estimated annual energy and cost savings per dollar of funding ......................... xvi

1. Calculating energy and cost savings for a single project area in a single state ..........9

2. Estimated annual nationwide energy and cost savings for 17 project areas

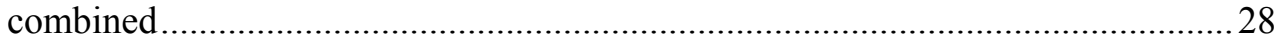





\section{LIST OF TABLES}

Table

Page

ES.1. Estimated relative magnitude of state-reported funding, by project area ............... xii

ES.2. Estimated total annual nationwide energy and cost savings for combined

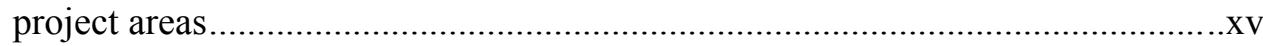

1. SEP project areas and performance metrics ...............................................

2. Reported expenditures of funds, by project area ............................................. 17

3. Number of states reporting activities in each project area ..................................2 20

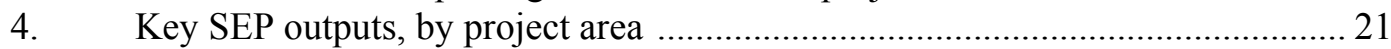

5. Estimated annual nationwide energy and cost savings, by project area .............. 23

6. Estimated annual nationwide emissions reductions, by project area .................... 24

7. Estimated annual nationwide funding and savings for combined project areas .... 25

A.1. Estimated energy savings from commercial sector training programs ................ 47

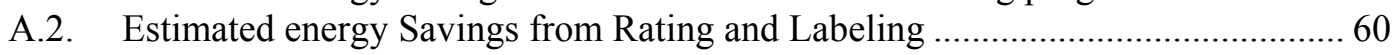

B.1. Emissions from each major fuel type, in metric tons per million source BTUs .... 70

B.2. Fuel mix for key energy use sectors or activities.......................................... 71

B.3. Average emissions for key energy use sectors or activities, in metric tons per

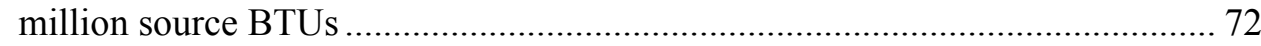





\section{ABBREVIATIONS, ACRONYMS, AND INITIALISMS}

$\begin{array}{ll}\text { AFV } & \text { Alternative Fuel Vehicles } \\ \text { ASHRAE } & \text { American Society of Heating, Refrigerating and Air Conditioning } \\ & \text { Engineers } \\ \text { BTU } & \text { British Thermal Unit } \\ \text { CBECS } & \text { Commercial Building Energy Consumption Survey } \\ \text { CNG } & \text { Compressed Natural Gas } \\ \text { CO } & \text { Carbon Monoxide } \\ \text { CTA } & \text { Collaborative Targeted Assessment } \\ \text { DOE } & \text { Department of Energy } \\ \text { E-85 } & \text { 85\% Ethanol } \\ \text { EEMs } & \text { Energy-Efficiency Mortgage } \\ \text { EERE } & \text { Office of Energy Efficiency and Renewable Energy } \\ \text { EIA } & \text { Energy Information Administration } \\ \text { EPA } & \text { Environmental Protection Agency } \\ \text { FAQs } & \text { Frequently Asked Questions } \\ \text { FEMP } & \text { Federal Energy Management Program } \\ \text { GPRA } & \text { Government Performance and Results Act } \\ \text { HERS } & \text { Home Energy Rating System } \\ \text { IAC } & \text { Industrial Assessment Center } \\ \text { ICP } & \text { Industrial Conservation Program } \\ \text { IEEC } & \text { International Energy Efficiency Code } \\ \text { LED } & \text { Light-Emitting Diode } \\ \text { LPG } & \text { Liquefied Petroleum Gas } \\ \text { MEC } & \text { Model Energy Code } \\ \text { NASEO } & \text { National Association of State Energy Officials } \\ \text { NOX } & \text { Nitrogen Oxide } \\ \text { ORNL } & \text { Oak Ridge National Laboratory } \\ \text { PBF } & \text { Public Benefits Fund } \\ \text { PG\&E } & \text { Pacific Gas and Electric } \\ \text { PM10 } & \text { Fine Particulate Matter } \\ \text { PV } & \text { Photovoltaic } \\ \text { PVE } & \text { Petroleum Violation Escrow } \\ \text { SECP } & \text { State Energy Conservation Program } \\ \text { SEP } & \text { State Energy Program } \\ \text { SO } 2 & \text { Sulphur Dioxide } \\ \text { VMT } & \text { Vehicle Miles Traveled } \\ \text { VOCs } & \text { Volatile Organic Compounds } \\ \text { WAP } & \text { Weatherization Assistance Program } \\ & \\ & \\ & \end{array}$





\section{EXECUTIVE SUMMARY}

Oak Ridge National Laboratory (ORNL) has performed an evaluation for the U.S. Department of Energy (DOE) to quantify the nationwide energy and cost savings and emissions reductions associated with a wide variety of energy efficiency and renewable energy activities performed by the states and territories during their 2002 program year under the State Energy Program (SEP). This is the second evaluation of SEP accomplishments performed by ORNL for DOE; the first one was completed two years ago and was documented by a January 2003 ORNL report.

This study utilizes a classification scheme that ORNL staff developed for describing the various activities supported by SEP funds. It involves describing a number of distinct project areas into which the states' various SEP efforts can be placed and identifying specific performance metrics within those broad areas that allow program accomplishments to be systematically measured. This classification scheme focuses almost exclusively on activities for which we could quantify energy savings.

The 18 project areas examined in this study are as follows:

- Mass Media

- School Education Programs

- Workshops/Training

- Retrofits

- Energy Audits

- Procurement of Energy-Efficient Products by Government Agencies

- Technical Assistance

- Loans and Grants

- Codes and Standards

- Rating and Labeling

- Home Energy Rating Systems (HERS) and Energy-Efficiency Mortgages (EEMs)

- Financial Incentives

- Interest Reduction Programs

- Alternative Energy

- Energy Emergency Planning

- Tax Credits

- Traffic Signals and Controls

- Carpools/Vanpools

For each project area, there are one or more performance metrics, each of which is a key action taken by the program or a direct customer response to those actions (e.g., number of energy audits performed, number of persons attending workshops and training sessions). In total, 32 distinct metrics were used in this evaluation. In addition, there are other types of SEPsupported activities performed by various states and territories that do not fall under the classification scheme used in this study. These include strategic planning and climate-change planning efforts; policy development and energy legislation; telecommuting programs; waste management and recycling efforts; water system efficiency projects; and various traffic-flow improvements not addressed by this study's metrics. 
All states, territories, and the District of Columbia were contacted in early June 2004 and asked to provide counts of specified SEP activities performed during their 2002 program year, along with all funding used to support those activities. For most states and territories, the SEP program year lags the federal fiscal year by nine months, so their 2002 program year covered the period from July 2002 through June 2003. By mid August 2004, all 50 states, the District of Columbia, and four of the five territories had provided the requested information.

The responding states and territories reported spending a total of $\$ 44.1$ million of SEP funds and \$542.0 million of funds from all sources-excluding Public Benefits Fund (PBF) monies-on the specified activities performed during program year 2002. These numbers do not include funding for two states that did not report their project expenditures. When the fiscal year 2002 SEP allocation for those two states (as shown in DOE records) was added, the amount of SEP funding for all 18 project areas increased from $\$ 44.1$ million to $\$ 46.7$ million. For the 17 project areas for which savings could be quantified (all areas except Energy Emergency Planning), the SEP contribution in support of the states' and territories' program year 2002 activities was $\$ 46.2$ million and the total expenditure was $\$ 540.9$ million.

As shown in Table ES.1, three-fourths or more of the responding states conducted activities using SEP funds in the areas of Workshops/Training, Mass Media, Technical Assistance, and Alternative Energy, and half or more engaged in activities related to Energy Audits, School Education, Retrofits, Loans and Grants, Codes and Standards, and Energy Emergency Planning.

Table ES.1. Relative magnitude of state-reported funding, by project area

\begin{tabular}{lccc}
\hline & $\begin{array}{l}\text { SEP funding as } \\
\text { percentage of total SEP } \\
\text { funding reported by all } \\
\text { states for all 18 project } \\
\text { areas (\%) }\end{array}$ & $\begin{array}{l}\text { All Funding } \\
\text { non-SEP) as percentage } \\
\text { of total reported by all } \\
\text { states for all 18 project } \\
\text { areas (\%) }\end{array}$ & $\begin{array}{l}\text { Number of } \\
\text { states } \\
\text { providing data }\end{array}$ \\
Project area & 16.2 & 15.3 & 34 \\
\hline Loans and Grants & 15.5 & 2.4 & 54 \\
Workshops/Training & 12.1 & 1.9 & 49 \\
Technical Assistance & 11.0 & 12.0 & 41 \\
Alternative Energy & 10.6 & 2.2 & 40 \\
Energy Audits & 9.6 & 1.3 & 49 \\
Mass Media & 8.1 & 1.0 & 28 \\
Codes and Standards & 7.1 & 38.5 & 36 \\
Retrofits & 4.1 & 0.6 & 38 \\
School Education Programs & 1.3 & 6.4 & 11 \\
Financial Incentives & 1.1 & 0.2 & 28 \\
Energy Emergency Planning & 0.8 & 0.1 & 7 \\
Rating and Labeling & 0.8 & 10.7 & 10 \\
Tax Credits & 0.5 & 0.1 & 14 \\
Procurement & 0.5 & 0.7 & 9 \\
Carpools and Vanpools & 0.4 & 5.3 & 5 \\
Interest Reduction Programs & 0.2 & 1.3 & 9 \\
Traffic Signals and Controls & 0.1 & 0.01 & 4 \\
HERS and EEMs & & & \\
\hline
\end{tabular}

${ }^{a}$ Public Benefits Fund contributions and the associated savings are excluded from this analysis because including them would substantially overstate SEP effects. 
On the other end of the scale, less than one-fourth of the states were active in the areas of Financial Incentives, Tax Credits, Carpools and Vanpools, Traffic Signals and Controls, Rating and Labeling, Interest Reductions, and HERS and EEMs. The five most heavily funded project areas (Loans and Grants, Workshops/Training, Technical Assistance, Alternative Energy, and Energy Audits) together accounted for nearly two-thirds of all SEP funding reported. The top 10 project areas (the top five plus Mass Media, Codes and Standards, Retrofits, School Education Programs, and Financial Incentives) accounted for over 95\% of all SEP funds reported. Not surprisingly, nearly all of the project areas receiving the largest share of SEP funding are also areas in which a majority of the responding states conducted activities.

For total funding (SEP plus non-SEP), Retrofits received the largest amount, followed by Loans and Grants, Alternative Energy, Tax Credits, and Financial Incentives. The project areas with the lowest total funding were HERS and EEMs, Rating and Labeling, Procurement, Emergency Planning, and Carpools and Vanpools. While the lists of highest- and lowest-funded project areas for SEP alone and for all sources combined have a number of similarities, there are also notable differences. The reason for this is that some project areas received substantially more funds from non-SEP sources than did others.

SEP funding and support contributed to a tremendous number and variety of outputs, including over 100,000 attendees at workshops and training sessions, state adoption of 22 new residential building codes and 20 non-residential codes, the auditing of almost 325 million square feet of floor space and the retrofitting of another 153 million square feet, over a third of a million technical assistance contacts, and the provision of approximately $\$ 46$ million of tax credits, $\$ 30$ million of loans, $\$ 21$ million of rebates, and $\$ 12$ million of grants.

Estimates of the savings resulting from each activity covered by the performance metrics were developed by ORNL staff in 17 of the project areas listed previously. Those estimates were expressed in terms of the amount of energy saved for a single activity (e.g., per residential energy audit) and are referred to in this report as "per-unit savings multipliers" or "energy-savings coefficients." They were taken from recent evaluations focusing on the effects of various state energy efficiency and renewable energy programs. We were not able to develop per-unit savings multipliers for Energy Emergency Planning, which focuses primarily on dealing with supply shortage and interruptions rather than saving energy. In all other project areas, the energy-savings coefficients were multiplied by state-provided information on the number of activities undertaken to calculate energy savings. Those energy-savings numbers were, in turn, multiplied by statespecific energy prices to provide estimates of cost savings. Finally, the energy and cost savings estimates were each multiplied by a state-specific PBF adjustment factor to remove the savings associated with the states' PBF expenditures. This last step was considered necessary because of the extremely large magnitude of PBF expenditures relative to SEP funding in many states that have a PBF.

It should be noted that the estimates of energy savings per activity used in this study generally were taken from a limited number of evaluations and were applied broadly to the entire SEP. They do not fully account for variations among participants that could affect the energy savings achieved, thus introducing a degree of uncertainty into the results. Still, this study is the most comprehensive and rigorous evaluation of the SEP undertaken to date, and the resulting numbers can be considered reasonable estimates of the savings associated with the SEP-supported activities performed by the states and territories. 
Figure ES.1 graphically illustrates the proportion of estimated annual nationwide energy savings achieved in each project area for which outcomes were quantified. Workshops and Training accounted for slightly more than $22 \%$ of total energy savings, while the area of Codes and Standards was responsible for nearly $20 \%$ of the savings that occurred. Energy Audits accounted for almost $16 \%$ of overall savings, Retrofits provided roughly another $11 \%$, and Technical Assistance contributed an additional $7 \%$ of the total annual savings achieved by the states. Between them, these five areas generated slightly more than three-fourths of total savings. The next five highest energy-saving areas were Traffic Signals and Controls; Financial Incentives; Alternative Energy; Mass Media; and Tax Credits. Savings in the top 10 areas combined accounted for more than $94 \%$ of total energy savings. Project areas with the greatest savings often had participation by a majority of the states and also had a built-in mechanism for multiplying the savings achieved (e.g., a single building code affects thousands of new structures; a single workshop attendee influences several different buildings).

Estimated annual energy savings as percent of total savings in all project areas

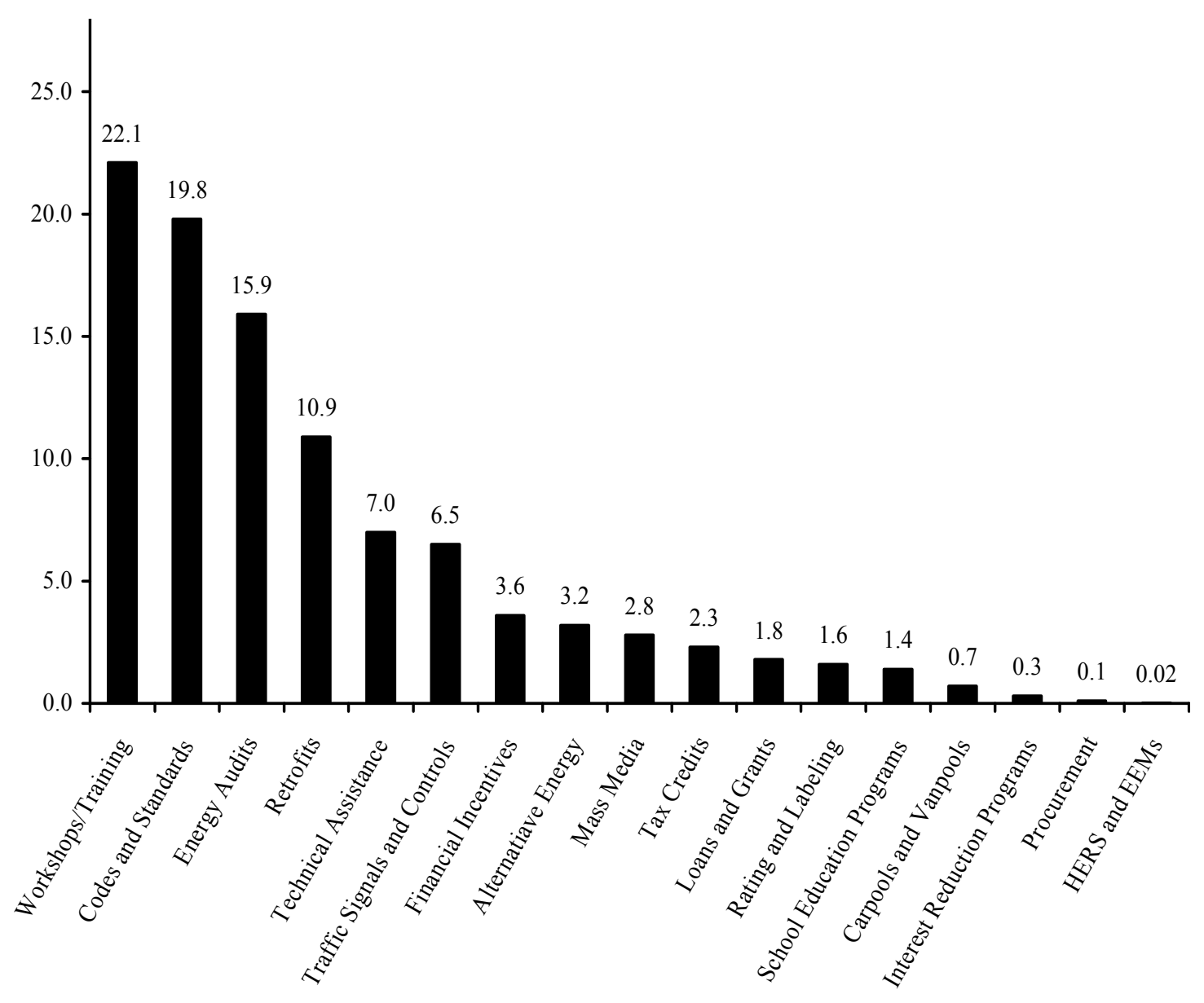

Figure ES.1. Estimated annual nationwide energy savings by project area 
In all 17 project areas for which outcomes were quantified, estimated annual energy savings from the activities performed by the states and territories during their 2002 program year totaled 47.6 trillion source BTUs and cost savings exceeded \$333 million (Table ES.2). We know that the State Energy Program contributed to these outcomes, but we cannot say with certainty what portion of the measured outcomes is directly attributable to the support and influence provided by SEP, because this study was not designed to distinguish that from the portion of outcomes that would have occurred even without the stimulus provided by the SEP. However, we do know that the activities that generated the energy and cost savings were classified by the responding states and territories as "SEP projects," defined as those undertakings for which the SEP contribution was "important."

Dividing the estimated total annual savings numbers by the state-reported SEP expenditures made in support of the relevant state activities shows that each dollar of SEP funding was associated with annual savings of 1.03 million source BTUs and \$7.22. Dividing the estimated annual saving numbers by the total expenditures from all sources (SEP + non-SEP) in the same 17 project areas shows annual savings of 0.09 million source BTUs and $\$ 0.62$ per dollar of total funding (Fig. ES.2). Because the same savings numbers are used in both sets of calculations, the difference between the savings per SEP dollar and savings per total dollar is due to the difference in the amount of money committed by the various sources. And because the energy and cost savings reported here are annual savings numbers and are expected to continue for many years to come, lifetime savings are expected to greatly exceed the total investment required to achieve them.

Table ES.2. Estimated total annual nationwide energy and cost savings for combined project areas ${ }^{a}$

\begin{tabular}{cc}
$\begin{array}{c}\text { Estimated annual energy savings } \\
\text { (trillion source BTUs) }\end{array}$ & $\begin{array}{c}\text { Estimated annual cost savings } \\
\text { (million \$) }\end{array}$ \\
\hline
\end{tabular}

${ }^{a}$ The estimated savings shown in this table are for all 17 project areas for which outcomes were quantified. See Chapter 3 for a discussion of how to interpret the energy savings estimates in light of the uncertainties associated with them.

Emissions reductions were calculated by multiplying the estimated energy savings achieved within each project area and energy-use sector by coefficients representing average emissions per million source BTUs for that project area and sector for six different emissions types. Because the numbers are based on energy savings, the relative magnitude of the reduction achieved in each individual project area is the same as for energy savings. For all 17 project areas for which savings were quantified, total carbon emissions were reduced by approximately 826,000 metric tons annually, sulphur-dioxide $\left(\mathrm{SO}_{2}\right)$ emissions declined by about 8,500 metric tons per year, annual emissions of nitrogen oxide $\left(\mathrm{NO}_{\mathrm{x}}\right)$ went down by 6,200 metric tons, yearly emissions of carbon monoxide (CO) were reduced by 1,000 metric tons, and emissions of fine particulate matter (PM10) and volatile organic compounds (VOCs) were reduced by approximately 160 and 130 metric tons per year, respectively. 
To put the above findings in perspective, the annual estimated energy saving of 47.6 trillion source BTUs is equivalent to the average amount of energy used for all non-transportation applications in more than 289,000 U.S. households over the course of an entire year. And the annual carbon reduction of 826,000 metric tons is the same as all the carbon emissions produced by over 582,000 passenger cars in a one-year period.

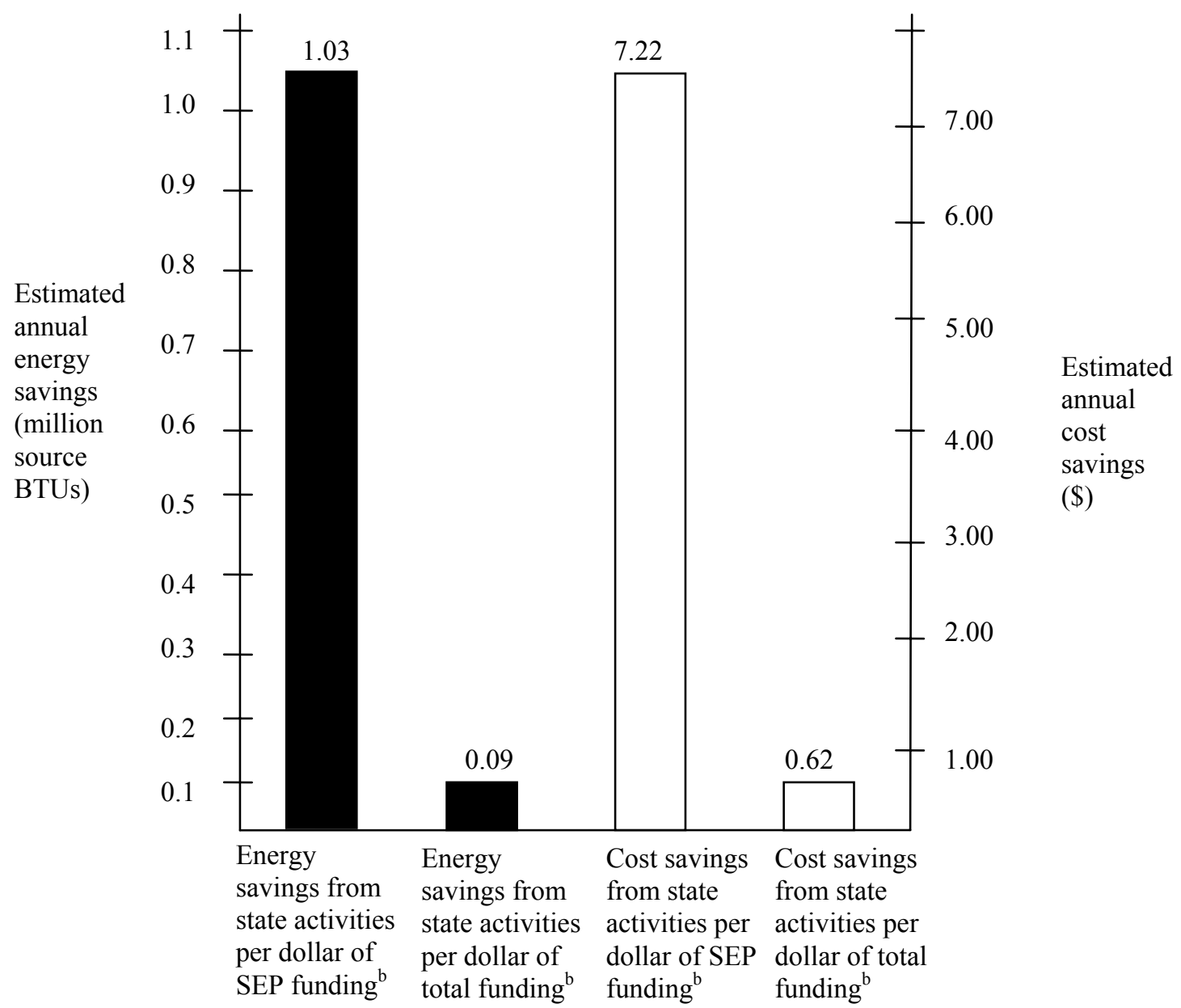

\footnotetext{
${ }^{\mathrm{a}} \mathrm{See}$ Chapter 3 for a discussion of how to interpret the energy-savings estimated in light of the uncertainties associated with them.

${ }^{b}$ Funding includes everything reported by the states (except for Public Benefits Funds) for the 17 project areas for which savings were estimated plus SEP allocations provided by DOE for two states that did not report funding.
}

\section{Fig. ES.2 Estimated annual energy and cost savings per dollar of funding ${ }^{\mathrm{a}}$}

The energy efficiency and renewable energy activities performed by the states and territories have resulted in substantial energy and cost savings and emissions reductions, but the exact proportion of those outcomes that is attributable to the State Energy Program is not known. This study indicates that there is a very broad array of valuable project types available to the states, each of which serves important needs and is part of a balanced energy efficiency and renewable energy portfolio that is likely to vary from state to state and year to year. 


\section{INTRODUCTION}

\section{PROGRAM DESCRIPTION}

The U.S. Department of Energy's (DOE's) State Energy Program (SEP) was established in 1996 by merging the State Energy Conservation Program (SECP) and the Institutional Conservation Program (ICP), both of which had been in existence since 1976 (U.S. DOE 2001a). The SEP provides financial and technical assistance for a wide variety of energy efficiency and renewable energy activities undertaken by the states and territories. SEP provides money to each state and territory according to a formula that accounts for population and energy use. In addition to these "Formula Grants," SEP "Special Project" funds are made available on a competitive basis to carry out specific types of energy efficiency and renewable energy activities (U.S. DOE 2003c). The resources provided by DOE typically are augmented by money and in-kind assistance from a number of sources, including other federal agencies, state and local governments, and the private sector.

The states' SEP efforts include several mandatory activities, such as establishing lighting efficiency standards for public buildings, promoting car and vanpools and public transportation, and establishing policies for energy-efficient government procurement practices. The states and territories also engage in a broad range of optional activities, including holding workshops and training sessions on a variety of topics related to energy efficiency and renewable energy, providing energy audits and building retrofit services, offering technical assistance, supporting loan and grant programs, and encouraging the adoption of alternative energy technologies. The scope and variety of activities undertaken by the various states and territories is extremely broad, and this reflects the diversity of conditions and needs found across the country and the efforts of participating states and territories to respond to them.

The purpose of this report is to present estimates of the energy and cost savings and emissions reductions associated with SEP activities performed by the states during the 2002 program year, based on primary data provided by the states themselves. This is the second systematic evaluation of SEP accomplishments performed by Oak Ridge National Laboratory (ORNL) for DOE. A report documenting the findings of the first study was published in January 2003 (Schweitzer et.al., 2003).

\section{SEP PERFORMANCE METRICS}

Over the last several years, ORNL staff have developed and refined a classification scheme for describing the various activities supported by SEP funds. This involves describing a number of distinct project areas into which the states' various SEP efforts can be placed and identifying specific performance metrics within those broad areas that allow program accomplishments to be systematically measured. Each performance metric is a key action taken by the program (e.g., number of printed materials distributed, number of energy audits performed) or a direct customer response to those actions (e.g., number of materials downloaded from state websites, number of persons attending workshops). As shown in Table 1, under the current framework there are 18 distinct project areas, most of which have one or two metrics associated with them. Altogether, there are 32 metrics; this represents a significant simplification from the previous SEP evaluation, which used nearly 80 metrics in 20 project areas. 
Table 1. SEP project areas and performance metrics

\begin{tabular}{|c|c|}
\hline Mass Media & $\begin{array}{l}\text { Number of downloads from internet websites } \\
\text { of printed materials, by sector (residential, } \\
\text { commercial, industrial, institutional, } \\
\text { transportation, agricultural) } \\
\text { Number of printed materials distributed, by } \\
\text { sector }\end{array}$ \\
\hline School Education Programs & $\begin{array}{l}\text { - Number of K-12 students taught with } \\
\text { instructional units developed or distributed by } \\
\text { program }\end{array}$ \\
\hline Workshops/Training & $\begin{array}{l}\text { Number of persons attending workshops and } \\
\text { training sessions, by sector (residential, } \\
\text { commercial, industrial, institutional, } \\
\text { transportation, agricultural) }\end{array}$ \\
\hline Retrofits & $\begin{array}{l}\text { Number of buildings retrofit, by type of } \\
\text { building (residential, general commercial, } \\
\text { school, health care, state government, } \\
\text { industrial) } \\
\text { - Building square footage, by building type }\end{array}$ \\
\hline Energy Audits & $\begin{array}{l}\text { - Number of energy audits performed, by } \\
\text { sector (residential, commercial, industrial, } \\
\text { institutional) } \\
\text { - } \quad \text { Total floor space audited, by sector } \\
\text { - } \quad \text { Total projected energy savings, by sector }\end{array}$ \\
\hline $\begin{array}{l}\text { Procurement of Energy-Efficient Products by } \\
\text { Government Agencies }\end{array}$ & $\begin{array}{l}\text { Number of energy-efficient units purchased, } \\
\text { by type (vehicles, office equipment, HVAC, } \\
\text { streetlights, exit signs) }\end{array}$ \\
\hline Technical Assistance & $\begin{array}{l}\text { - Number of contacts in which energy } \\
\text { efficiency or renewable energy measures } \\
\text { were recommended, by sector (residential, } \\
\text { commercial, industrial, institutional, } \\
\text { transportation, agricultural) }\end{array}$ \\
\hline Loans and Grants & $\begin{array}{l}\text { - Monetary value of loans made, by sector } \\
\text { (residential, commercial, industrial, } \\
\text { institutional, transportation, agricultural) } \\
\text { - } \quad \text { Monetary value of grants given, by sector }\end{array}$ \\
\hline
\end{tabular}


Table 1. (Continued)

Codes and Standards

Rating and Labeling

Home Energy Rating Systems (HERS) and Energy Efficiency Mortgages (EEMs)

Financial Incentives

Interest Reduction Programs

Alternative Energy
- Name of new energy-efficiency building code adopted at state or local level, by building type (residential, commercial, institutional, industrial)

- Name of old energy-efficiency building code replaced by new code at state or local level, by building type

- Approximate percentage of new construction in state covered by new energy-efficiency building code

- Approximate percentage of new appliances sold in state covered by new, mandatory energy-efficiency appliance standard, by appliance type (refrigerator, clothes washer, dishwasher, water heater, room air conditioner)

- Types of energy-consuming devices for which energy-efficiency rating and labeling systems were endorsed by the state (office computer/monitor, home computer/monitor, fax machine, copier, multifunction device, scanner, printer, TV, VCR, TV/VCR, audio equipment, room air conditioner, dishwasher, refrigerator, clothes washer)

- Number of EEMs issued

- Monetary value of rebates provided, by sector (residential, commercial, industrial, institutional, transportation, agricultural)

- Monetary value of interest reductions provided, by sector (residential, commercial, industrial, institutional, transportation, agricultural)

- Number of alternative fuel vehicles purchased by state and local government agencies

- Number of conventional vehicles converted by state and local government agencies to allow alternative fuel use 
Table 1. (Continued)

Alternative Energy (continued)

Energy Emergency Planning

Tax Credits

Traffic Signals and Controls

Carpools/Vanpools
- Number of hybrid electric vehicles purchased by state and local government agencies

- Number of private sector alternative fuel vehicle refueling stations added as a result of SEP actions or partnership efforts

- Number of megawatts of wind-powered generating capacity installed with program assistance

- Number of megawatts of photovoltaic generating capacity installed with program assistance

- Number of energy emergency plans developed by state and local governments, by topic (transportation fuels, heating fuels, electricity)

- Monetary value of tax credits given, by sector (residential, commercial, industrial, institutional, transportation, agricultural)

- Number of energy-efficient lightemitting diode (LED) traffic signals installed

- Number of street lane-miles for which synchronized traffic signals are installed

- Number of new carpools/vanpools formed

It must be noted that our classification scheme focused almost exclusively on activities for which energy savings could be quantified, which is a substantial but partial subset of all SEP activities. In addition to the metrics presented above, there were other types of energy efficiency and renewable energy activities in which the states and territories engaged. These include: strategic planning and climate-change planning efforts; policy development and energy legislation; telecommuting programs; waste management and recycling efforts; water system efficiency projects; and various traffic-flow improvements not addressed by this study's metrics.

In the terminology of the Government Performance and Results Act (GPRA), the performance metrics shown in Table 1 describe program "outputs," which are broadly defined as activities or efforts that can be expressed in a quantitative or qualitative manner. These are 
distinguished from "outcomes," which are the ultimate results of the program compared to its intended purpose (in this case, energy and cost savings and emissions reductions). As shown in Chapter 2, the metrics used in this study serve as the basis for estimating the savings and emissions reductions associated with the State Energy Program. However, this study does not attempt to determine the exact proportion of measured outcomes that can be attributed to the efforts of the State Energy Program as opposed to the other entities (state government, private sector) that helped support the state activities addressed in this report.

While this study measures energy and cost savings and emissions reductions, it does not attempt to quantify other important benefits that also are associated with the SEP. These include positive effects on national security, the economy, and individual health and safety. For instance, many of the activities performed by alternative energy programs are aimed at decreasing petroleum consumption and increasing the nation's energy security rather than reducing the absolute amount of energy consumed, and those benefits are not quantified in this study. Also, this study does not quantify the achievements of state energy emergency plans, which help communities address possible supply shortages and interruptions but typically do not cut the total amount of energy used. Activities in other project areas also can have important economic, social, and national security benefits in addition to the energy and costs savings and emissions reductions that they engender. These non-energy benefits are important, and intended, products of the SEP and contribute substantially to its social value.

\section{SCOPE OF REPORT}

Subsequent chapters of this report provide additional information on the methods used to quantify SEP activities and accomplishments and the major findings of that effort. Chapter 2 describes how performance metrics data were collected and how energy and cost savings and emissions reductions were calculated from them. In Chapter 3, we discuss how to interpret the energy savings estimates in light of the uncertainties associated with them. Chapter $\mathbf{4}$ provides information on program funding and describes the key activities performed by the states and the outputs associated with those efforts. In Chapter 5, we report the energy and cost savings and emissions reductions achieved by the states and territories, overall and in the various project areas. Chapter 6 summarizes the key findings reported earlier and offers some conclusions regarding State Energy Program performance. 


\section{METHODS}

\section{DATA COLLECTION}

ORNL prepared a set of 18 spreadsheets, one for each broad project area, that elicited information on the number of activities performed under each performance metric. The specific information requested is shown in Table 1. The states and territories were instructed to report all SEP project activities (those supported by Formula Grand and those utilizing Special Projects funds) that were performed during their 2002 program year, along with all funding used to support those activities. For most states and territories, the SEP program year lags the federal fiscal year by nine months, so their 2002 program year covered the period from July 2002 through June 2003. In most cases, separate information on the activities performed was requested for each of the major energy-use sectors served (e.g., residential, commercial, institutional). Based on our experience with the previous study, a precise definition of what constitutes SEP projects and what non-SEP funding sources should be counted (which was developed with substantial input from the states) was provided ${ }^{1}$.

In early June of 2004, the National Association of State Energy Officials (NASEO) sent an electronic version of the data collection spreadsheets to the appropriate staff in each state and territory and asked them to fill them in and return them within one month. To facilitate the data collection process, NASEO invited all relevant state staffers to participate in a conference call to discuss the contents of the spreadsheets. That call was held in mid June and involved over 40 state and territory representatives, all the DOE regional offices, NASEO, and ORNL staff. A second call was held about a week later to accommodate states that had been unable to participate in the first call. During both sessions, NASEO and ORNL staff responded to questions posed by the states and attempted to clarify any points of confusion.

Following the first conference call, NASEO prepared a list of Frequently Asked Questions (FAQs) and distributed them to all the state and territorial energy offices. In addition, some states called or e-mailed NASEO or ORNL with individual questions and those were answered also. All of the above actions were taken to reduce the difficulties that individual states might have in providing the requested information, to ensure that the information they did provide was consistent from state to state, and to encourage the highest possible response rate.

By mid August, 2004, all 50 states, the District of Columbia, and four of the five U.S. territories had provided the requested data for this study. This means that we essentially have a census (i.e., the full population) as opposed to a sample. This allows us to draw conclusions about the State Energy Program without having to draw inferences or extrapolate from a subset of the entire population. In the last study, we received data from 20 states, so the current results represent a great improvement.

NASEO sent the completed spreadsheets to ORNL as soon as they were received, and ORNL staff examined all the state-provided data. Follow-up calls were made to a number of states and

\footnotetext{
${ }^{1}$ In the spreadsheets, it was clearly stated that, in order to be considered an SEP project, a project must be included in the State Plan submitted to SEP or be considered eligible for the State Plan if it was initiated after the plan was already submitted. Also, SEP funds must be used to support the project and the SEP contribution should be important (although it is possible that the project might still exist, but in diminished form, in the absence of the SEP contribution). The states were instructed to report ALL resources used to support their SEP projects.
} 
territories, as necessary, to clarify responses or elicit additional information. Also, a number of calls were made to states to check on outliers (i.e., unusually large numbers). The information provided by the states in response to the follow-up contacts were used to revise (or confirm) the numbers contained in the final data set.

\section{CALCULATING SAVINGS AND EMISSIONS REDUCTIONS}

For the previous SEP evaluation, ORNL staff developed estimates of energy savings resulting from the activities covered by the performance metrics in 14 different project areas ${ }^{2}$. These savings estimates were expressed in terms of the amount of energy saved for a single activity (e.g., per residential energy audit; per dollar of industrial sector grant). In this report, these savings estimates are referred to as "per-unit savings multipliers" or "energy-savings coefficients," because they can be multiplied by the total number of activities performed to yield estimates of overall savings for a given performance metric.

The energy-savings coefficients described above were taken from recent evaluations that focused on the effects of various state energy efficiency and renewable energy programs. A number of articles published in journals and conference proceedings were reviewed, and findings were extracted from those that were relevant to the SEP and employed rigorous and well-accepted research methods. An effort was made to keep the energy-savings coefficients conservative by adjusting them downward to account for factors such as installation, savings-realization, and compliance rates, where appropriate.

For the current study, ORNL staff reviewed all of the energy-savings coefficients used in the previous study in light of the latest available data and revised them as necessary. We also developed coefficients for three additional project areas ${ }^{3}$. In addition, within the previouslyaddressed project areas, savings estimates were developed for a number of energy-use sectors that had not been covered in the first study. As a result, we were able to calculate energy savings for 17 of the 18 project areas (all except Energy Emergency Planning) and for every energy-use sector in nearly all of those 17 areas $^{4}$. We were not able to locate good data on the magnitude of energy savings associated with the development of energy emergency plans, probably because the primary focus of such efforts is on helping state and local governments deal with supply shortages and interruptions rather than reducing energy consumption.

\footnotetext{
${ }^{2}$ Energy savings were expressed in terms of millions of British Thermal Units (BTUs), regardless of the fuel involved, to allow the combination of savings by different fuel types. Where the fuel in question was electricity, kilowatt hours were converted to source BTUs (i.e., the amount of energy required at the power plant to produce a specified amount of usable energy), using the formula: one $\mathrm{kWh}=0.010883$ million source BTUs. If electricity savings were expressed in site BTUs, they were converted to source BTUs by multiplying by 3.189. Source BTUs were used as the common unit of measurement to reflect the total amount of energy saved.

${ }^{3}$ The three additional project areas for which energy savings coefficients were developed are: Mass Media; School Education Programs; and Alternative Energy.

${ }^{4}$ In three project areas (Loans and Grants, Financial Incentives, and Interest Reduction Programs) we were unable to develop energy-savings coefficients for the Transportation sector due to a lack of data on program results.
} 
It should be noted that the estimates of energy savings per activity used here were generally taken from a limited number of evaluations and were applied broadly to the entire State Energy Program. They do not fully account for variations among participants that could affect the energy savings achieved, thus introducing a degree of uncertainty into the results. Despite this, the current study represents the most comprehensive and rigorous evaluation of the SEP performed to date, and the savings numbers presented in this document can be considered reasonable estimates of what has been accomplished by the SEP-supported activities performed by the states and territories. A detailed discussion of all the energy-savings coefficients used and how they were developed is provided in Appendix A.

Figure 1 presents a conceptual diagram of how energy and cost savings were calculated from the counts of program activities and the energy-savings coefficients for a single project area in a single state ${ }^{5}$. To start, the number of reported activities of a single type (e.g., institutional retrofits performed) was multiplied by the associated per-unit savings coefficient. Even in those project areas that had only one performance metric, it was common for there to be more than one activities number and associated coefficient, because activities were disaggregated by the energyuse sector addressed and the multipliers typically varied by sector. Once all of the activities

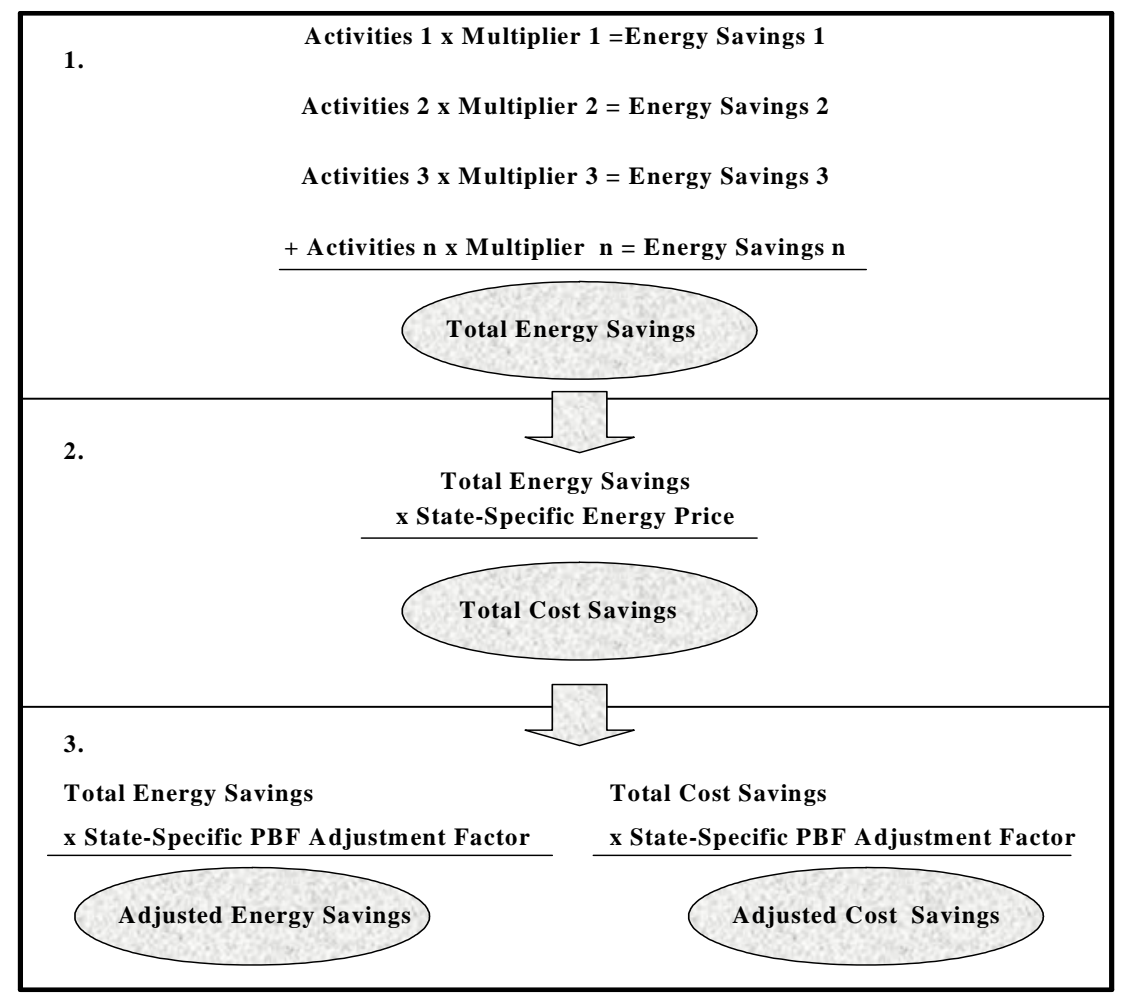

Fig. 1 Calculating energy and cost savings for a single project area in a single state

${ }^{5}$ For a few project areas, step 1 does not precisely describe the method used to calculate energy savings, either because multiple activities were not reported (School Education; HERS and EEMs; Carpools and Vanpools) or the process started with an estimate of national savings that was then adjusted downward based on state-level construction (Codes and Standards) or appliance sales (Rating and Labeling). Even in those cases, however, steps 2 and 3 accurately describe the process used to calculate cost savings and adjust cost and energy savings. 
in the project area were multiplied by the appropriate coefficient to yield savings estimates, all of those savings numbers were summed to give total energy savings. This energy savings number for the project area, expressed in millions of source BTUs, was then multiplied by the statespecific energy $\operatorname{cost}^{6}$ (Energy Information Administration 2003a), expressed in dollars per million source BTUs, to produce an estimate of total cost savings. Finally, the energy and cost savings estimates were each multiplied by a state-specific Public Benefits Fund (PBF) adjustment factor to yield adjusted savings numbers ${ }^{7}$. The PBF adjustment factor removed the savings associated with a state's Public Benefits Fund expenditures, which was considered necessary because of their extremely large magnitude relative to SEP funding in many states that have a PBF. In many cases, PBF expenditures reflect plans and priorities that are established independently of the State Energy Program. Accordingly, including these funds and the resulting savings in this study would substantially overstate SEP effects.

The savings numbers calculated in the above manner for a single project area and state provide the building blocks for a number of different summations that can be performed. Using these numbers, totals can be calculated for a given project area for all states combined, for all project areas for a single state, and for all project areas for all states. However, we cannot say with certainty what portion of those savings is attributable to the support provided by the State Energy Program and what portion may be due to other influences.

Emissions reductions were calculated directly from the energy-savings estimates discussed above. Essentially, the amount of savings achieved by each state within each project area and energy-use sector was multiplied by coefficients representing average emissions per million source BTUs for that project area and sector for six different emissions types: Carbon; Nitrogen Oxide $\left(\mathrm{NO}_{\mathrm{x}}\right)$; Sulphur Dioxide $\left(\mathrm{SO}_{2}\right)$; Volatile Organic Compounds (VOCs); Carbon Monoxide (CO); and Fine Particulate Matter (PM10). For each project area, the emissions reductions of each type achieved by the various sectors were summed to get total emissions reductions for that area. Then, the project area emissions for all states were summed to yield total emissions reductions for all states combined. A more detailed description of this process, with illustrative tables, is presented in Appendix B.

After all data were collected and analyzed, a draft report was prepared documenting the study findings and the methods used to develop them. The discussion of methods contained in that report (including a detailed appendix describing how each energy-savings coefficient was developed) was reviewed by the Board of Directors of the International Energy Program Evaluation Conference, Inc. (IEPEC), a group of highly-qualified professionals with extensive experience in evaluating

${ }^{6}$ The weighted average national energy price used in this study was $\$ 6.78$ per million source BTUs. The state-specific costs ranged from a low of \$4.47 in Montana to a high of \$10.22 in the District of Columbia.

7 The PBF adjustment factor was calculated by taking the amount of total funding for a given project area (SEP plus all non-SEP) and subtracting the amount of PBF funding from it. This number was divided by total funding to get a factor representing non-PBF funding as a proportion of all funding. This factor was then multiplied by total savings to yield an estimate of the amount that was generated without PBF money, based on the assumption that the amount of savings generated by PBF funds is roughly proportional to the amount of funding provided by that source. In reality, determining the attribution of savings is a more complicated matter, but the method described here was used because it was all that the available data would allow. 
energy efficiency programs. The six-member panel provided an objective third-party peer review of the performance metrics used in the ORNL study (Vine et.al. 2005). In response to comments provided by the IEPEC review panel, we made adjustments to the energy-savings coefficients associated with nine performance metrics in eight of the project areas. 


\section{HOW TO INTERPRET THE ENERGY SAVINGS ESTIMATES}

\section{FACTORS INFLUENCING UNCERTAINTY OF RESULTS}

If the full effects of every SEP-supported action taken by each state and territory were thoroughly examined and directly measured, and the influence of the State Energy Program was isolated from all other influences on the observed outcomes, the reported impacts of the program could be accepted with certainty. However, such an undertaking would require a massive stateby-state and project-by-project data collection and analysis effort which would far exceed the resources available for the current study. Instead, this study estimated the probable outcomes of state actions based on the past performance of similar types of efforts. In a study of this type, there are a number of factors that introduce uncertainty into the estimates of energy savings and, consequently, into the cost savings and emissions reductions numbers which are derived from them. The four major factors related to uncertainty of results in this case are: (1) imprecision of the energy-savings multipliers used; (2) incomplete coverage of state activities; (3) the attribution of savings; and (4) the exclusion of certain benefits from the analysis. Each of these four factors is discussed briefly below.

\section{Imprecision of energy-savings multipliers}

As explained in the Methods chapter, energy savings were calculated from state-reported counts of specified activities and estimates of the average savings generated by a single activity of each type ("per-unit savings multipliers"). In most cases, those multipliers were taken from a limited number of recent evaluations of state energy efficiency and renewable energy efforts. Typically, the results of multiple studies were averaged and the mean energy-savings figure was multiplied by the number of relevant activities reported by each state and territory to yield a savings estimate. The resources available to perform this evaluation did not allow us to examine the specific activities performed by every state and calculate unique savings numbers for each one. Instead, we relied on savings averages, which are unlikely to reflect the exact results achieved in each individual case.

There are a number of ways in which the energy-savings multipliers used in this study did not fully account for variations among participants that could affect the energy savings achieved. Each multiplier represents the savings resulting from a specific defined activity (e.g., a workshop attendee receiving information on a set of four common energy efficiency measures or technologies), but the actual characteristics of the real activities in which participants engage (e.g., the measures covered in a particular workshop) are likely to vary from case to case. Other important factors that vary among participants include the types and sizes of buildings and facilities affected and climatic conditions. In addition, some of the behavioral response factors used in developing the multipliers (e.g., the percent of participants taking some type of action) were applied uniformly across multiple energy-use sectors when, in reality, participant responses could vary by sector.

Because the multipliers used in this study represent estimates of average savings rather than precise measurements of individual performance, it is likely that the outcomes calculated from them differ to some extent from the actual results achieved by any given state. We expect actual savings to be greater than estimated savings in some cases and less than estimated savings in others. However, it should be noted that an effort was made throughout this study to keep the 
energy-savings multipliers conservative (i.e., to err on the side of underestimation) by the definitions of specific activities that were chosen and by adjusting savings downward to account for factors such as installation and compliance rates.

\section{Incomplete coverage of state activities}

As noted in the Introduction, the classification scheme used in this study did not cover all SEP-supported activities performed by the various states and territories. In fact, the expenditures reported by respondents for all the covered activities accounted for less than three-quarters of the total funding distributed by the State Energy Program during its 2002 fiscal year. It is highly probable that those expenditures that fell outside our classification scheme resulted in additional energy and cost savings and emissions reductions, but the magnitude of those outcomes is unknown. If all SEP-supported expenditures were tracked and all associated savings were measured, it is likely that the annual energy and cost savings associated with each SEP dollar spent by the states and territories would be different than the numbers given in this report.

\section{Attribution of savings}

In this study, the states and territories were asked to report their activities only for "SEP projects," which were defined as those for which the SEP contribution was "important." Despite this, it cannot be assumed that SEP is responsible for all the savings associated with the activities that it supports, because those activities typically receive funding from other sources (e.g., state government agencies, private firms) and some of those contributors might have engaged in the activities in question even without SEP's support and influence. In addition, there are other factors (e.g., energy costs, other public and private sector programs) that can independently encourage the types of activities that SEP promotes. Accordingly, attributing savings to the appropriate sources can be difficult.

It seems clear that the magnitude of outcomes attributable to any given source is not directly proportional to the amount of funding it provides. That is because a program (like SEP) can influence other entities to provide funding and in-kind support that would otherwise not have been made available. However, the fact that the SEP contribution was "important" does not mean it was the only factor influencing the activities performed by the states and territories. All that can safely be concluded from the current study is that the State Energy Program contributed to the observed savings; the precise amount of those savings for which SEP can take credit is not known.

\section{Exclusion of certain benefits}

The current study did not address certain benefits that are widely recognized as contributing to the value of energy efficiency and renewable energy programs. Spillover and networking effects occur when participants take what they learn from program activities and apply them in other situations or pass on the relevant knowledge and attitudes to others. These effects can amplify the energy and cost savings that are generated by a given program.

In addition to the energy and cost savings that are associated with SEP-supported activities, there are a variety of non-energy benefits that can occur. These include positive effects on national security, the economy, and community health and safety. A recent study of the nonenergy benefits associated with the national Weatherization Assistance Program found that the 
estimated value of the non-energy benefits achieved by that program was slightly greater than the value of energy savings over the lifetime of the installed measures (Schweitzer and Tonn 2002). It is likely that non-energy benefits could also be very substantial for the activities performed under the State Energy Program. Accordingly, if the non-energy benefits and spillover effects associated with the SEP were measured, the additional value would probably be significant.

\section{COMBINED EFFECT OF UNCERTAINTY FACTORS}

From the above discussion, it is clear that there is uncertainty associated with the findings presented in this document. The imprecision of the energy-savings multipliers can introduce error into the reported findings. The overall effect of that can be to either exaggerate or understate actual savings, although efforts were made throughout the study to keep the energysavings multipliers conservative. The incomplete coverage of state activities and the exclusion of certain benefits both have the effect of underestimating actual savings. And the fact that the current study did not address the attribution of benefits means that the State Energy Program cannot be assigned sole credit for all the observed outcomes.

The combined effect of all the above factors is that the savings numbers presented in this document should be treated as estimates of the outcomes associated with the State Energy Program rather than as definitive measures of program accomplishments. Despite this uncertainty, a review of the study's methods conducted by the Board of Directors of the International Energy Program Evaluation Conference concluded that this effort "provides a reasonable estimate of the impacts of the SEP programs" (Vine et. al. 2005). 


\section{PROGRAM FUNDING AND ACTIVITIES}

\section{FUNDING BY PROJECT AREA}

Table 2 shows the amount of funding spent in each of the 18 project areas in support of the activities performed by the states during their 2002 program year. The table shows the funding provided by SEP alone and by all funding sources (SEP plus non-SEP, excluding PBF). In addition, funding in each project area as a percent of total funding for all project areas combined - both for SEP funding alone and for all funding sources - is shown. The range of SEP funding extended from a high of over $\$ 7$ million (for Loans and Grants) to a low of less than $\$ 25$ thousand for HERS and EEMs.

Table 2. Reported expenditures of funds, by project area

\begin{tabular}{|c|c|c|c|c|}
\hline Project area & $\begin{array}{l}\text { SEP } \\
\text { funding (\$) }\end{array}$ & $\begin{array}{l}\text { SEP funding } \\
\text { as percent of } \\
\text { total SEP } \\
\text { funding } \\
\text { reported by } \\
\text { all states for } \\
\text { all } 18 \text { project } \\
\text { areas (\%) }\end{array}$ & $\begin{array}{l}\text { All } \\
\text { funding: } \\
\text { SEP + all } \\
\text { non-SEP } \\
\text { (\$) }\end{array}$ & $\begin{array}{l}\text { All funding } \\
\text { (SEP + non- } \\
\text { SEP) as } \\
\text { percentage of } \\
\text { total reported } \\
\text { by all states for } \\
\text { all } 18 \text { project } \\
\text { areas (\%) }\end{array}$ \\
\hline Loans and Grants & $7,128,721$ & 16.2 & $83,061,761$ & 15.3 \\
\hline Workshops/Training & $6,850,898$ & 15.5 & $13,264,137$ & 2.4 \\
\hline Technical Assistance & $5,348,816$ & 12.1 & $10,374,661$ & 1.9 \\
\hline Alternative Energy & $4,868,186$ & 11.0 & $64,920,694$ & 12.0 \\
\hline Energy Audits & $4,656,049$ & 10.6 & $12,054,512$ & 2.2 \\
\hline Mass Media & $4,231,971$ & 9.6 & $6,889,206$ & 1.3 \\
\hline Codes and Standards & $3,570,502$ & 8.1 & $5,481,662$ & 1.0 \\
\hline Retrofits & $3,129,285$ & 7.1 & $208,424,740$ & 38.5 \\
\hline School Education Programs & $1,831,615$ & 4.1 & $3,260,101$ & 0.6 \\
\hline Financial Incentives & 560,873 & 1.3 & $34,702,830$ & 6.4 \\
\hline Energy Emergency Planning & 486,165 & 1.1 & $1,157,920$ & 0.2 \\
\hline Rating and Labeling & 366,166 & 0.8 & 374,666 & 0.1 \\
\hline Tax Credits & 365,713 & 0.8 & $57,825,567$ & 10.7 \\
\hline Procurement & 221,898 & 0.5 & 595,854 & 0.1 \\
\hline Carpools and Vanpools & 207,670 & 0.5 & $3,947,006$ & 0.7 \\
\hline Interest Reduction Programs & 171,070 & 0.4 & $28,447,698$ & 5.3 \\
\hline Traffic Signals and Controls & 85,052 & 0.2 & $7,179,670$ & 1.3 \\
\hline HERS and EEMs & 24,525 & 0.1 & 68,058 & 0.01 \\
\hline $\begin{array}{l}\text { Total reported for all } 18 \text { project } \\
\text { areas }\end{array}$ & $44,105,175$ & 100.0 & $542,030,743$ & 100.0 \\
\hline
\end{tabular}

a Public Benefits Fund contributions and the associated savings are excluded from this analysis because including them would substantially overstate SEP effects. 
The five most heavily funded project areas (Loans and Grants, Workshops and Training, Technical Assistance, Alternative Energy, and Energy Audits) together accounted for nearly twothirds of all SEP funding reported. The top 10 project areas (the top five plus Mass Media, Codes and Standards, Retrofits, School Education Programs, and Financial Incentives) accounted for over $95 \%$ of all SEP funds reported. Not surprisingly, nearly all of the project areas receiving the largest share of SEP funding are also areas in which a majority of the responding states conducted activities. All of the top five SEP-funded project areas were in the top eight in the previous study, indicating that the distribution of funds has not changed radically since the last SEP evaluation.

For all funding (SEP plus non-SEP), Retrofits received the largest amount, followed by Loans and Grants, Alternative Energy, Tax Credits, and Financial Incentives. The project areas with the lowest total funding were HERS and EEMs, Rating and Labeling, Procurement, Energy Emergency Planning, and School Education Programs. While the lists of highest- and lowestfunded project areas for SEP alone and for all sources combined have a number of similarities, there are also notable differences. Retrofits, Tax Credits, and Interest Reduction Programs all did much better in terms of total funding than for SEP funds alone, while Workshops and Training, Technical Assistance, Energy Audits, Mass Media, and Codes and Standards did substantially worse. The reason for this is that some project areas received substantially more funds from non-SEP sources than did others. DOE's Office of Energy Efficiency and Renewable Energy (EERE) will further analyze the non-SEP funding for the 18 project areas to better understand the impact SEP dollars had on leveraging non-SEP funding.

\section{OVERALL FUNDING}

As shown at the bottom of Table 2, the states and territories reported that they had spent a total of \$44.1 million of SEP funds and \$542 million of funds from all sources (excluding PBF monies) to support the activities performed during their 2002 program year in the 18 project areas covered in this evaluation. After adding the fiscal year 2002 SEP allocation shown in DOE records for two states that failed to report any expenditures, the SEP total increased to $\$ 46.7$ million. However, according to DOE's records, the total amount of money distributed during its 2002 fiscal year-for Formula Grants and Special Projects combined—was \$63.8 million. This raises an important question: why is the amount reported by the states in this study so much less than the actual amount allocated by DOE?

There are several possible answers to the above question. One possibility is that, for some states, the SEP activities performed during their 2002 program year did not exhaust all the fiscal year 2002 funding allocated to them by DOE. However, it should be noted that the states were instructed to report all funding used to support the activities performed during their 2002 program year, so it is possible that some money allocated by DOE in previous fiscal years was included in the state-reported expenditures.

Another possibility is that some states under-reported the actual amount of money they spent in the 18 project areas. A thorough examination of the state-provided data shows that, with the exception of two states that provided no funding data whatsoever, there were very few 
instances in which a state reported activities in a given area without providing funding data for that same area. And those few cases were balanced by a number of instances in which a state reported funding in a particular area without reporting any activities covered by the performance metrics. However, it is likely that some states did not report SEP funds spent on employee salaries and other administrative expenses.

It is our belief that the primary reason the state-reported total is smaller than the DOE total is that the performance metrics used in our study did not cover all of the SEP-supported activities performed by the states. Our classification scheme focused almost exclusively on activities for which energy savings could be quantified, which is a substantial but partial subset of all SEP activities. In the 18 project areas that we identified, it is likely that some states performed activities that did not fit into our performance metrics framework. In addition, we know that the states and territories took some actions that fell outside those project areas. These include the following broad types of activities: strategic planning and climate-change planning efforts; policy development and energy legislation; telecommuting programs; waste management and recycling efforts; water system efficiency projects; and various traffic-flow improvements not addressed in this study's metrics. Specific activities in the above areas include: developing comprehensive energy plans and greenhouse gas mitigation plans; assessing the carbon dioxide releases associated with different agricultural crops; giving policy direction to state governments for utility deregulation options; providing training and resource materials for telework pilot programs; supporting demonstration programs related to efficiency improvements for municipal water and waste plants; and implementing rapid response systems to clear disabled vehicles from freeways and maintain traffic flow. It is considered probable that activities of those types, which did not fit into the classification scheme used in this study, accounted for most of the nonreported funds. EERE will conduct a follow-up study to better understand the basis of the funding discrepancy.

\section{STATE ACTIVITIES BY PROJECT AREA}

The number of states reporting activities in each project area is shown in Table 3. Clearly, there is substantially more activity in some areas than in others. All of the responding states and territories, except one, were involved in providing Workshops and Training for their constituents. At least three-fourths of the states were active in the areas of Mass Media, Technical Assistance, and Alternative Energy, and half or more engaged in activities related to Energy Audits, School Education, Retrofits, Loans and Grants, Codes and Standards, and Energy Emergency Planning. On the other end of the scale, less than one-fourth of the responding states were active in the areas of Financial Incentives, Tax Credits, Carpools and Vanpools, Traffic Signals and Controls, Rating and Labeling, Interest Reductions, and HERS and EEMs.

The project areas with the most and least state involvement reported above are very similar to those reported by responding states in the last study. In fact, the 10 project areas in which at least half of the states reported participating this time are the same areas in which half or more of the responding states were involved during the last study. And those areas with the least state involvement in this study also showed the lowest rates of participation the last time. 
Table 3. Number of states reporting activities in each project area

\begin{tabular}{lc}
\hline Project area & Number of states reporting activities \\
\hline Workshops/Training & 54 \\
Mass Media & 49 \\
Technical Assistance & 49 \\
Alternative Energy & 41 \\
Energy Audits & 40 \\
School Education & 38 \\
Retrofits & 36 \\
Loans and Grants & 34 \\
Codes and Standards & 28 \\
Energy Emergency Planning & 28 \\
Procurement & 14 \\
Financial Incentives & 11 \\
Tax Credits & 10 \\
Carpools and Vanpools & 9 \\
Traffic Signals and Controls & 9 \\
Rating and Labeling & 7 \\
Interest Reduction & 5 \\
HERS and EEMs & 4 \\
\hline
\end{tabular}

\section{KEY OUTPUTS}

Table 4 illustrates the large variety and magnitude of outputs associated with SEP-funded activities reported by the states and territories. It shows that over 100,000 persons attended workshops and training sessions and that nearly 340,000 technical assistance contacts were provided. In the area of mass media, almost 2.5 million materials were downloaded from internet websites and nearly that many printed materials were distributed to program clients. Almost 325 million square feet of floor space were audited, and another 153 million square feet were retrofitted with program assistance. Over $\$ 30$ million of loans were made by SEP-supported projects and an additional $\$ 12$ million of grants were given. Nearly $\$ 46$ million of tax credits and more than $\$ 21$ million of rebates (Financial Incentives) were provided. Twenty-two states reported adopting new residential building codes and 20 adopted new commercial or other nonresidential codes. A more complete listing of program outputs is provided in the table. 
Table 4. Key outputs, by project area

\begin{tabular}{|c|c|}
\hline Project area & Key outputs for all states combined \\
\hline Workshops/Training & 102,067 persons attended workshops and training sessions \\
\hline Codes and Standards & $\begin{array}{l}22 \text { states adopted new residential code } \\
20 \text { states adopted new commercial or other non-residential code }\end{array}$ \\
\hline Energy Audits & $\begin{array}{l}15,264 \text { audits performed } \\
324,997,295 \text { square feet of floor space audited }\end{array}$ \\
\hline Retrofits & $\begin{array}{l}12,896 \text { buildings retrofit } \\
153,130,899 \text { square feet of buildings retrofit }\end{array}$ \\
\hline Technical Assistance & $\begin{array}{l}339,054 \text { contacts in which energy efficiency or renewable energy } \\
\text { measures were recommended }\end{array}$ \\
\hline Traffic Signals and Controls & $\begin{array}{l}\text { 92,488 energy-efficient LED traffic signals installed } \\
1,007 \text { street lane-miles covered by synchronized traffic signals }\end{array}$ \\
\hline Mass Media & $\begin{array}{l}2,497,849 \text { printed materials downloaded from internet web sites } \\
2,408,880 \text { printed materials distributed }\end{array}$ \\
\hline Financial Incentives & $\$ 21,535,033$ of rebates provided \\
\hline Alternative Energy & $\begin{array}{l}6,434 \text { alternative fuel vehicles purchased or converted } \\
205 \text { alternative fuel refueling stations added } \\
73.18 \text { megawatts of wind or photovoltaic generating capacity installed }\end{array}$ \\
\hline Tax Credits & $\$ 45,828,885$ of tax credits given \\
\hline Loans and Grants & $\begin{array}{l}\$ 30,403,388 \text { of loans made } \\
\$ 12,345,608 \text { of grants given }\end{array}$ \\
\hline Rating and Labeling & 7 states endorsed energy efficiency rating systems \\
\hline School Education Programs & 604,050 students taught \\
\hline Carpools and Vanpools & 4,136 new carpools or vanpools formed \\
\hline Interest Reduction Programs & $\$ 3,765,658$ of interest reductions provided \\
\hline Procurement & 11,759 energy-efficient units purchased \\
\hline HERS and EEMs & 207 Energy Efficiency Mortgages issued \\
\hline Energy Emergency Planning & 78 energy emergency plans developed \\
\hline
\end{tabular}




\section{ENERGY AND COST SAVINGS AND EMISSIONS REDUCTIONS}

\section{SAVINGS AND EMISSIONS REDUCTIONS BY PROJECT AREA}

Of the 18 project areas discussed in the previous chapters, we were able to develop energy-savings coefficients for all of them except Energy Emergency Planning. Table 5 presents the estimated annual nationwide energy and cost savings achieved in each of the 17 project areas for which savings could be calculated. Workshops and Training accounted for slightly more than $22 \%$ of total energy savings, while the area of Codes and Standards was responsible for nearly $20 \%$ of the savings that occurred. Energy Audits accounted for almost $16 \%$ of overall savings, Retrofits provided roughly another $11 \%$, and Technical Assistance contributed an additional $7 \%$ of the total annual savings achieved by the states. Between them, these five areas generated slightly more than three-fourths of total savings. The next five highest energy-saving areas were Traffic Signals and Controls; Financial Incentives; Alternative Energy; Mass Media; and Tax Credits. Savings in the top 10 areas combined accounted for more than $94 \%$ of total energy savings. Eight of those 10 project areas were among the top ten energy-saving areas in the previous evaluation, and three of the top five energy-saving project areas this time (Workshops and Training, Codes and Standards, and Energy Audits) were among the top five in the previous study.

Table 5. Estimated annual nationwide energy and cost savings, by project area ${ }^{a}$

\begin{tabular}{lcccc}
\hline & $\begin{array}{l}\text { Estimated } \\
\text { annual energy } \\
\text { sumber } \\
\text { of states }\end{array}$ & $\begin{array}{l}\text { Estimated } \\
\text { source BTUs) }\end{array}$ & $\begin{array}{l}\text { Estimated energy } \\
\text { annual cost } \\
\text { savings (\$) }\end{array}$ & $\begin{array}{l}\text { total savings in all } \\
\text { project areas (\%) }\end{array}$ \\
\hline Workshops/Training & 54 & $10,500,000$ & $75,700,000$ & 22.1 \\
Codes and Standards & 28 & $9,400,000$ & $63,700,000$ & 19.8 \\
Energy Audits & 40 & $7,600,000$ & $50,900,000$ & 15.9 \\
Retrofits & 36 & $5,200,000$ & $38,900,000$ & 10.9 \\
Technical Assistance & 49 & $3,400,000$ & $23,600,000$ & 7.0 \\
Traffic Signals and Controls & 9 & $3,100,000$ & $20,800,000$ & 6.5 \\
Financial Incentives & 11 & $1,700,000$ & $12,500,000$ & 3.6 \\
Alternative Energy & 41 & $1,500,000$ & $10,700,000$ & 3.2 \\
Mass Media & 49 & $1,300,000$ & $9,200,000$ & 2.8 \\
Tax Credits & 10 & $1,100,000$ & $7,800,000$ & 2.3 \\
Loans and Grants & 34 & 830,000 & $5,800,000$ & 1.8 \\
Rating and Labeling & 7 & 750,000 & $5,900,000$ & 1.6 \\
School Education Programs & 38 & 660,000 & $4,500,000$ & 1.4 \\
Carpools and Vanpools & 9 & 350,000 & $2,100,000$ & 0.7 \\
Interest Reduction Programs & 5 & 160,000 & $1,100,000$ & 0.3 \\
Procurement & 14 & 50,000 & 350,000 & 0.1 \\
HERS and EEMs & 4 & 10,000 & 50,000 & 0.02 \\
\hline Total & 55 & $47,600,000$ & $333,600,000$ & 100.0 \\
\hline
\end{tabular}

\footnotetext{
${ }^{\text {a }}$ See Chapter 3 for a discussion of how to interpret the energy-savings estimates in light of the uncertainties associated with them. ${ }^{\mathrm{b}}$ In addition to the energy savings shown above, Alternative Energy activities also reduced the petroleum consumption by approximately 210,000 barrels.
} 
It is not surprising that Workshops and Training and Codes and Standards were the two highest-saving areas in this study because, in addition to being addressed by a majority of the states and territories, each has a built-in mechanism for multiplying the savings achieved. In the case of Workshops and Training, recipients of program services in most energy-use sectors are expected to apply the lessons learned several times (e.g., each institutional trainee is expected to influence energy savings in four different buildings). For Codes and Standards, the adoption of a single code typically influences thousands of new structures every year, so the savings achieved can be considerable even if per-unit savings are relatively modest. For the other three project areas in the top-five savings group, all had participation by at least $65 \%$ of the states and territories and one (Technical Assistance) tends to amplify its savings because participants in most sectors are expected to influence several different buildings or vehicles.

The smallest amount of energy savings occurred in the areas of HERS and EEMs, Procurement, Interest Reduction Programs, and Carpools and Vanpools. In all cases, activities in these project areas were undertaken by approximately one-fourth of fewer (usually much fewer) of the responding states, and the amount of SEP funding allocated to them was relatively small. These four project areas are the same ones where energy savings were found to be lowest in the previous study.

Estimated emissions reductions are based directly on the energy savings described above. Accordingly, the rank order of the project areas, and the relative magnitude of the outcomes achieved in each one, are the same for emissions reductions (Table 6) as for energy savings (Table 5).

Table 6. Estimated annual nationwide emissions reductions in metric tons, by project area

\begin{tabular}{lcccccc}
\hline & Carbon & $\begin{array}{l}\text { Sulphur } \\
\text { Dioxide } \\
\left.\mathbf{S O}_{\mathbf{2}}\right)\end{array}$ & $\begin{array}{l}\text { Nitrogen } \\
\text { Oxide } \\
\left(\mathbf{N O}_{\mathbf{x}}\right)\end{array}$ & $\begin{array}{l}\text { Carbon } \\
\text { Monoxide } \\
(\mathbf{C O})\end{array}$ & $\begin{array}{l}\text { Fine } \\
\text { Particulate } \\
\text { Matter } \\
\text { (PMlO) }\end{array}$ & $\begin{array}{l}\text { Volatile } \\
\text { Organic } \\
\text { Compounds } \\
\text { (VOCs) }\end{array}$ \\
\hline Workshops/Training & 185,000 & 2,100 & 1,400 & 230 & 40 & 30 \\
Codes and Standards & 159,000 & 1,650 & 1,300 & 220 & 30 & 30 \\
Energy Audits & 132,000 & 1,500 & 1,100 & 170 & 30 & 20 \\
Retrofits & 89,300 & 950 & 720 & 120 & 20 & 15 \\
Technical Assistance & 57,800 & 630 & 450 & 75 & 10 & 10 \\
Traffic Signals and Controls & 57,800 & 160 & 120 & 20 & 3 & 2 \\
Financial Incentives & 29,000 & 300 & 240 & 40 & 6 & 5 \\
Alternative Energy & 27,200 & 300 & 220 & 35 & 5 & 5 \\
Mass Media & 23,200 & 270 & 180 & 30 & 4 & 4 \\
Tax Credits & 17,500 & 190 & 140 & 25 & 4 & 3 \\
Loans and Grants & 14,200 & 150 & 120 & 20 & 3 & 3 \\
Rating and Labeling & 13,400 & 150 & 110 & 20 & 3 & 2 \\
School Education Programs & 10,400 & 110 & 90 & 15 & 2 & 2 \\
Carpools and Vanpools & 6,600 & 0 & 0 & 0 & 0 & 0 \\
Interest Reduction Programs & 2,700 & 30 & 20 & 5 & 1 & 1 \\
Procurement & 900 & 10 & 10 & 1 & 0 & 0 \\
HERS and EEMs & 120 & 1 & 1 & 0 & 0 & 0 \\
\hline Total & 826,000 & 8,500 & 6,200 & 1,000 & 160 & 130 \\
\hline
\end{tabular}




\section{TOTAL SAVINGS AND EMISSIONS REDUCTIONS}

As shown at the bottom of Table 5, estimated annual nationwide energy savings totaled approximately 47.6 trillion source BTUs for all 17 project areas for which outcomes were quantified. These savings were calculated from the activities performed by the states and territories during their 2002 program year. For those same activities, estimated annual cost savings exceeded $\$ 333$ million. These annual energy and cost savings are likely to continue over time, because the effects of the SEP-supported energy-saving measures tend to last for many years. The total savings reported here are somewhat higher than the national totals documented in the previous study (41.4 trillion source BTUs and \$256.4 million), which is not surprising because the current evaluation calculated savings for three project areas and some project-specific end-use sectors that were not covered in the first study.

This study was not designed to distinguish the outcomes achieved as a result of SEP support and influence from those outcomes that would have occurred even without the stimulus provided by the State Energy Program. The magnitude of outcomes attributable to a given source is not directly proportional to the amount of funding provided because a program (like SEP) can leverage funds from other sources that would otherwise not have been used for such efforts. Accordingly, we can confidently assert that the State Energy Program contributed to the outcomes described above, but the exact proportion of those outcomes that are attributable to the SEP itself is not known.

For the 17 project areas for which outcomes were quantified, each SEP dollar that the states and territories reported spending to support their 2002 program year activities was associated with annual energy savings of 1.03 million source BTUs $(47,600,000$ million BTU/\$46,231,836) and annual cost savings of $\$ 7.22(\$ 333,600,000 / \$ 46,231,836)$, as shown in Table 7. Each dollar of total reported expenditures (SEP plus non-SEP) resulted in annual energy savings of 0.09 million source BTUs $(47,600,000$ million BTU/\$540,872,823) and annual cost savings of $\$ 0.62(\$ 333,600,000 / \$ 540,872,823)$. Because the same estimated savings numbers are used in both sets of calculations, the difference between the savings per SEP dollar and savings per total dollar is due to the difference in the amount of money committed by the various sources.

Table 7. Estimated annual nationwide funding and savings for combined project areas ${ }^{\mathrm{a}}$

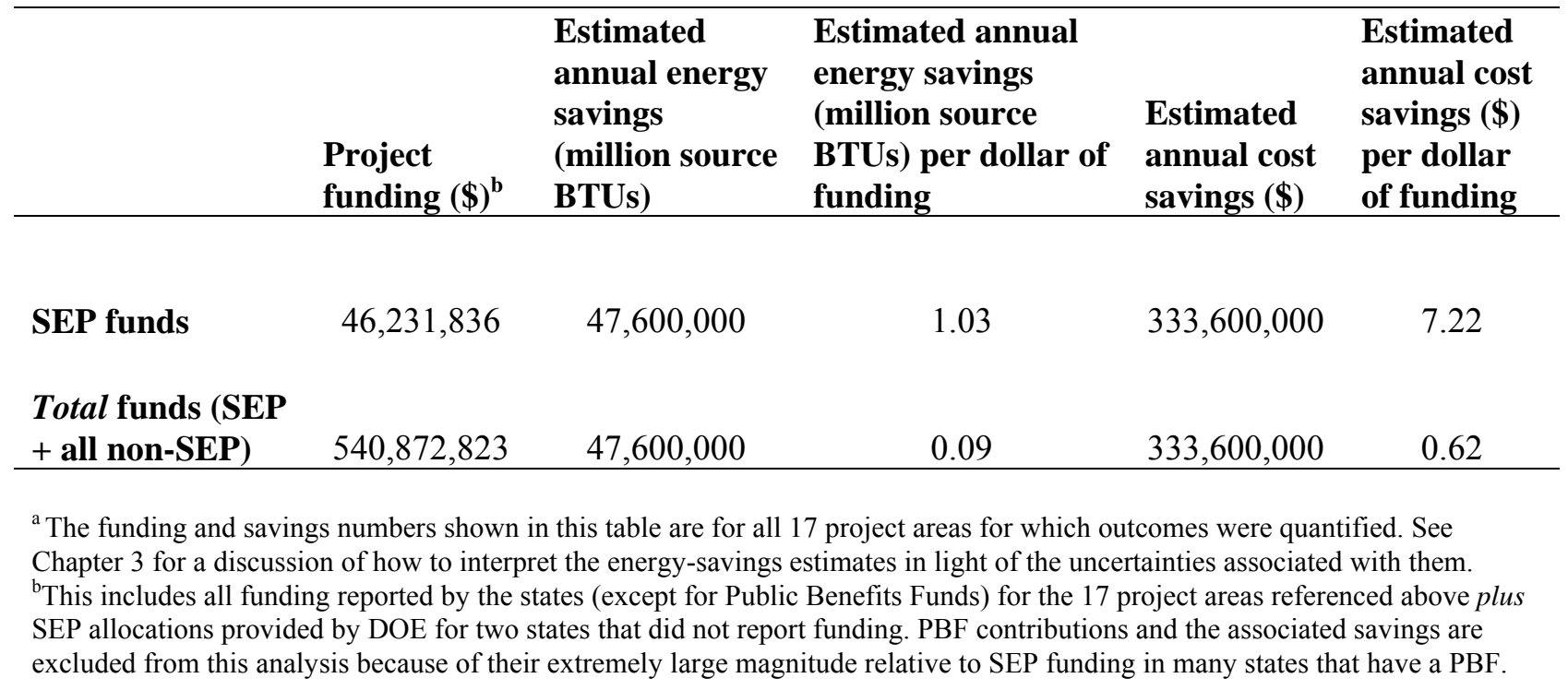


The previous study found remarkably similar savings per SEP dollar. At that time, it was estimated that each SEP dollar spent by the states and territories was associated with annual energy savings of 1.17 million source BTUs and cost savings of \$7.23. However, the outcome per total dollar of expenditures (SEP plus non-SEP) was found to be much higher in the last study than in this one. The previous evaluation found that each dollar of total expenditures led to annual savings of 0.25 million BTUs and $\$ 1.58$, which are roughly two and a half times the perdollar savings numbers found in this study. The simple explanation for this is that the amount of funding received from non-SEP sources was much higher this time than last time. This means that program savings in this study were divided by a much larger total funding number, reducing the outcomes per dollar accordingly. We suspect that total funding did not actually increase dramatically between the last study and this one, but that the states did a much more thorough job this time of reporting all funding used to support their SEP activities.

As shown at the bottom of Table 6 , it is estimated that annual nationwide carbon emissions were reduced by a total of 826,000 metric tons in the 17 project areas for which energy savings were quantified. The magnitude of emissions reductions was much smaller, but still considerable, for the other substances studied. Sulphur dioxide emissions were reduced by 8,500 metric tons per year, nitrogen oxide emissions decreased by more than 6,200 metric tons annually, and carbon monoxide reductions totaled approximately 1,000 metric tons each year. Emissions of fine particulate matter and Volatile Organic Compounds were reduced by approximately 160 and 130 metric tons per year, respectively. 


\section{SUMMARY AND CONCLUSIONS}

\section{SUMMARY OF FINDINGS}

All 50 states, the District of Columbia, and four of the five U.S. territories provided data for this study. A majority of the respondents were active in the areas of Workshops/Training, Mass Media, Technical Assistance, Alternative Fuels, Energy Audits, School Education, Retrofits, Loans and Grants, Codes and Standards, and Energy Emergency Planning. These project areas are largely the same as those that received the greatest amount of SEP funding, and both sets of programs have substantial overlap with those areas for which total funding (SEP plus non-SEP) was greatest.

The responding states and territories reported spending a total of \$44.1 million of SEP funds and $\$ 542.0$ million of funds from all sources (excluding PBF monies) to support the activities performed during their 2002 program year in all 18 project areas addressed by this study. These numbers do not include funding for two states that did not report their project expenditures. When the fiscal year 2002 SEP allocation for those two states (as shown in DOE records) was added, the amount of SEP funding for all 18 project areas increased from $\$ 44.1$ million to $\$ 46.7$ million. For the 17 project areas for which savings could be quantified (all areas except Energy Emergency Planning), the SEP contribution in support of the states' and territories' program year 2002 activities was $\$ 46.2$ million and the total expenditure was $\$ 540.9$ million.

SEP funding and support contributed to a tremendous number and variety of outputs, including over 100,000 attendees at workshops and training sessions, state adoption of 22 new residential building codes and 20 non-residential codes, the auditing of almost 325 million square feet of floor space and the retrofitting of another 153 million square feet, over a third of a million technical assistance contacts, and the provision of approximately $\$ 46$ million of tax credits, $\$ 30$ million of loans, \$21 million of rebates, and \$12 million of grants.

Of the total energy savings achieved by participating states and territories, slightly more than three-fourths occurred in the top five project areas: Workshops and Training; Codes and Standards; Energy Audits; Retrofits; and Technical Assistance. The next five highest energysaving areas were Traffic Signals and Controls; Financial Incentives; Alternative Energy; Mass Media; and Tax Credits. Project areas with the greatest savings often had participation by a majority of the states and also had a built-in mechanism for multiplying the savings achieved (e.g., a single building code affects thousands of new structures; a single workshop attendee influences several different buildings).

Annual nationwide energy and cost savings from the activities performed by the states and territories during their 2002 program year were estimated to total 47.6 trillion source BTUs and $\$ 333.6$ million, respectively, for all 17 project areas for which outcomes were quantified (Figure 2). Each SEP dollar that the states and territories reported spending to support their 2002 program year activities was associated with annual savings of 1.03 million source BTUs and $\$ 7.22$. Each dollar of total expenditures (SEP plus non-SEP) resulted in annual savings of 0.09 million source BTUs and $\$ 0.62$. Because the effects of the states' energy-saving activities tend to last for many years, the benefits continue to add up over time and are expected to greatly exceed the total investment required to achieve them. 
Total estimated emissions reductions were very large. Carbon reductions, at approximately 826,000 metric tons per year, were much greater than for all the other emissions categories combined. However, substantial reductions also were achieved for other emissions, most notably $\mathrm{SO}_{2}$ and $\mathrm{NO}_{x}$.

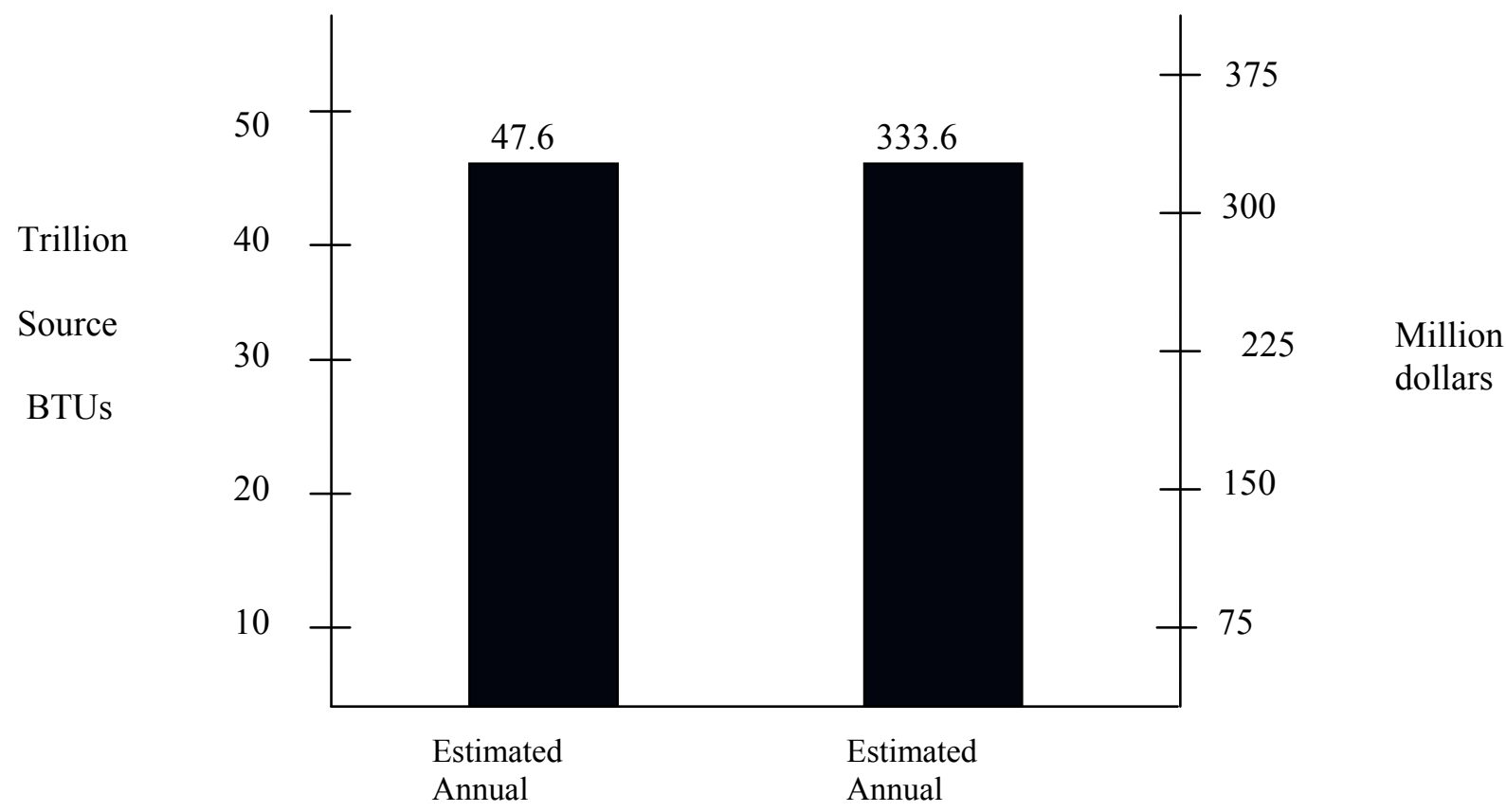

${ }^{\text {a }}$ See Chapter 3 for a discussion of how to interpret the energy-savings estimates in light of the uncertainties associated with them.

Figure 2. Estimated annual nationwide energy and cost savings for 17 project areas combined $^{a}$

To put the above findings in perspective, the estimated annual energy saving of 47.6 million source BTUs is equivalent to the average amount of energy used for all nontransportation applications in more than 289,000 U.S. households over the course of an entire year (EIA 2003b). And the annual carbon reduction of 826,000 metric tons is the same as all the carbon emissions produced by over 582,000 passenger cars in a one year period (U.S. EPA 2000).

\section{CONCLUSIONS}

The estimates given here of accomplishments associated with SEP-funded activities during the 2002 program year are based on counts of project activities provided by virtually every state and territory in the nation and on estimates of energy savings per action taken. They show that the energy efficiency and renewable energy activities performed by the states and territories have resulted in substantial energy and cost savings and emissions reductions. While the activities that generated those outcomes were labeled by the responding states and territories as "SEP projects" (defined as those undertakings for which the SEP contribution was "important"), the exact proportion of the outcomes that can be attributed to the State Energy Program, as opposed to other contributing influences, was not established by this study. 
Moving beyond overall accomplishments to examine individual project areas, it is clear that the types of projects vary considerably in their costs and benefits. Some receive large contributions of funds from non-SEP sources while others do not. Some generate substantial amounts of energy and cost savings, while the savings associated with others are considerably more modest. These differences are due to a variety of project characteristics, such as whether the effort represents a one-time stimulus or requires other actions to achieve the intended outcome, how many energy-consuming units are directly influenced by the action taken or by those receiving program services, and whether the project deals with mature technologies or tries to encourage new ones and build the associated infrastructure. It seems to us that no single type of project, regardless of how impressive its outcomes, is appropriate for all situations. Rather, there is a very broad array of valuable project types, each of which serves important needs and is part of a balanced energy efficiency and renewable energy portfolio that is likely to vary from state to state and year to year. The flexibility that SEP gives the individual state to determine what types of projects to support allows states to engage in those efforts that best fit the most pressing needs at hand.

Because the individual savings estimates that formed the basis of this study's savings calculations generally were taken from a limited number of studies, we recommend that findings from new evaluation studies be examined as they become available and that additional evaluations of selected SEP activities be undertaken to adjust (or corroborate) the existing savings numbers and to check key assumptions (e.g., responses to specific program services by end-use sector) that were used to calculate savings. In addition, future evaluations could be improved by more fully accounting for variations among participants that affect energy savings. This could include developing separate energy-savings multipliers for different climate zones and looking more closely at the specific activities of any given type that are performed by different participants. The key drawbacks to this more disaggregated approach are the increased time and resources required to develop the necessary multipliers and apply them to the activities data provided by the states and territories as well as the greater reporting burden for respondents.

The next study of the SEP should address the issue of "attribution" and identify the proportion of observed savings that are due to the support of the State Energy Program as opposed to other influences. Future studies should also address the issue of persistence of energy savings so that lifetime benefit-cost ratios can be calculated that account for the length of time that project-induced savings last. In addition, a fuller picture of the outcomes associated with the State Energy Program would be provided by adding an examination of non-energy benefits and spillover effects.

We recommend contacting individual states and territories to explore why the overall amount of state-reported project funding is substantially less than DOE's total SEP allocation. Such a study could show if there is a systematic under-reporting of project expenditures and could also provide additional information on activities that are an important part of states' SEP efforts but are not covered by the current set of performance metrics. In addition, further analysis of non-SEP funding should be performed to increase our understanding of the impact of SEP dollars on leveraging non-SEP funds.

In light of the fact that the performance metrics used in the current study are likely to be employed in future SEP evaluations, the individual states and territories would probably benefit from keeping track of their accomplishments using this study's key metrics. Initially, some states could require additional training or other types of assistance to establish the new tracking procedures. However, it is expected that the states' future reporting burden would be eased, because the information requested for subsequent evaluations would be readily available, and that 
the participating states would be more aware of key program outputs as they occur.

The states and territories would also benefit from continuing to encourage public and private sector involvement with their SEP activities, which increases the amount of support and financial assistance available to perform the projects at hand. 


\section{REFERENCES}

Abraham, M., and J. MacDonald, 1995. Energy and Conservation Opportunities in Small Commercial Buildings, ORNL/CON-414, Oak Ridge National Laboratory, Oak Ridge, Tennessee, August.

Applied Technology Research Corporation, 1995. Economic and Fiscal Impacts of the Energy Rated Homes of Louisiana Program, Prepared for Louisiana Department of Natural Research, March. www.leeric.lsu.edu/energy/impacts/intro.html

Barakat and Chamberlin, Inc., 1995. Impact and Process Evaluation of the Consolidated Edison Utility Low-Income Energy Efficiency Program (ULIEEP), prepared for Consolidated Edison Co., New York, New York.

Brown, M., and P. Mihlmeister, 1995. "Actual vs. Anticipated Savings from DSM Programs: An Assessment of the California Experience," Proceedings of the 1995 International Energy Program Evaluation Conference, Chicago, IL, pp. 295 - 301.

Building Systems Engineering and Building Systems Management, 2001. Energy Presentation to the $S A B$ 5/23/01. http://www.bsmesi.com/sab.html

City of Anaheim, 1998. Public Benefit Program: Energy Efficiency Incentives Program, Anaheim Public Utilities Department, June.

Clinton, J., H. Geller, and E. Hirst, 1986. "Review of Government and Utility Energy Conservation Programs," Annual Review of Energy 1986, 95-142.

Coates, B., 1995. "Persistence of Energy Savings in Commercial Buildings," 1995 Energy Program Evaluation Conference, 649-655, Chicago, IL.

Consortium for Energy Efficiency, 2001. Energy-Efficient Traffic Signals: Fact Sheet, http://www. ceeformt.org/resrc/facts/led-fx.php3

D \& R International, 2004. Estimated Energy Star Appliance Sales by State.

Direct Marketing Association, 2003. The DMA's 2003 Response Rate Study. http://www.thedma.org/cgi/dispnewsstand?article $=1570$

Energy Design Resources 2004. Design Briefs: Energy Management Systems. http://www.energydesignresources.com/resource/18

Energy Information Administration, 2000. Manufacturing Energy Consumption Survey, U.S. Department of Energy, Washington, DC.

Energy Information Administration, 2002a. 1999 Commercial Buildings Energy Consumption Survey. U.S. Department of Energy, Washington, DC. 
Energy Information Administration, 2002b. Estimated Number of Alternative-Fueled Vehicles in Use in the United States, by Fuel, 1993-2002, http://www.eia.gov/cneaf/alternate/page/datatables/ table1.html

Energy Information Administration, 2003a. Annual Energy Review 2002. U.S. Department of Energy, Washington, DC.

Energy Information Administration, 2003b. 2001 Residential Energy Consumption Survey, U.S. Department of Energy, Washington, DC.

ENERGY STAR website, 2000, http://www.energystar.gov

EnSave Energy Performance, Inc., 2002. Press Release: Water Cooled Milk Saves Money, April 25.

Equipoise Consulting, Inc., 2004. Final Report for Evaluation of the Agricultural Pumping Efficiency Program (CPUC Project 230-02ABCD), June 17.

Estes, K., 2004. Written communication from Kathy Estes, Energy Loan Program, Oregon Department of Energy, to Martin Schweitzer, Oak Ridge National Laboratory, September 3.

Federal Energy Management Program, 2004a. "How to Buy an Energy-Efficient Exit Sign," http://www.eere.energy.gov/femp/technologies/eep_exit_sign.cfm

Federal Energy Management Program, 2004b. FEMP Central Database, http://fempcentral.com/ fempcentral

Feldman, S. and B. Tannenbaum, 2000. "Swoosh!? Awareness and Effects of the ENERGY STAR BRAND in Wisconsin Appliance Efficiency Programs," ACEEE Summer Study 2000, 6.107-119, American Council for an Energy-Efficient Economy, Washington, DC.

Gettings, M.B., L.G. Berry, M.A. Beyer, and J.B. Maxwell, 1998. Validation of the National Energy Audit (NEAT) with Data from a Gas Utility Low-Income Residential Weatherization Program in New York State, ORNL/CON-457, Oak Ridge National Laboratory, Oak Ridge, Tennessee.

Greely, K., J. Harris, and A. Hatcher, 1990. "Measured Energy Savings and Cost-Effectiveness of Conservation Retrofits in Commercial Buildings," ACEEE 1990 Summer Study on Energy Efficiency in Buildings, American Council for an Energy-Efficient Economy, Washington, DC.

Green Building Services, 2001. Building-Integrated Photovoltaic Systems, PGE\#00228, Portland General Electric, Portland, Oregon.

Greene, D.L., 1986. Driver Energy Conservation Awareness Training: Review and Recommendations for a National Program, ORNL/TM-9897, Oak Ridge National Laboratory, Oak Ridge, TN, May. 
Hadley, D.L. and M.A. Halverson, 1993. Energy Conservation Potential of the U.S. Department of Energy Interim Commercial Building Standards, PNL-7967, Pacific Northwest Laboratory, Richland, WA, December.

Halverson, M. 2004. Personal Communication from Mark Halverson, Pacific Northwest National Laboratory, to Martin Schweitzer, Oak Ridge National Laboratory, August 3.

Hetrick, S., and C.B. McCollough, 1996. "How to Save \$4.2 Million a Year." ITS International Newsletter, June. http://www.benefitcost.its.dot.gov/ITS/benecost.nsf/0/ba0bcd8a17a881128525 69610051e29c?OpenDocument

Illinois Department of Commerce and Economic Opportunity, 2003. Illinois Energy Efficient Affordable Housing Program, June.

http://illinoisbiz.biz/com/energy/pdf/benefits\%20report\%207-03.pdf

Jones, D., Tonn, B., and Martin, M. 2002. Preliminary Estimation of Energy Management for the Best Practices Program. ORNL/TM-2002/134, Oak Ridge National Laboratory, Oak Ridge, TN, July.

Lap, Wes, 2002. "Wind Power Returns to America.” EV World: People and Technology.

Lew, V., and J. Wang, 1998. "Do Completed Projects Result in Energy Savings?” ACEEE

Summer Study 1998, 4.237-248, American Council for an Energy Efficient Economy, Washington, DC.

Louisiana Department of Natural Resources, 2001. Institutional Conservation Program, http://www.dnr.state.la.us/SEC/EXECDIV/TECHASMT/programs/institutional/icp.htm

Lucas, R. 2002. Assessment of Impacts from Adopting the 2000 International Energy Conservation Code for Residential Buildings in Illinois, PNNL-13835, Pacific Northwest National Laboratory, February.

Lucas, R. 2004. Personal Communication from Robert Lucas, Sr. Research Engineer, Pacific Northwest National Laboratory, to Martin Schweitzer, Oak Ridge National Laboratory, July 21 and August 4.

McRae, M.R., and J.S. Peters, 2003. Market Assessment of Green Light-Emitting Diode (LED) Traffic Lights in the Energy Trust's Service Territory, Funded by Energy Trust of Oregon, Inc., January.

Madison, K. and D. Baylon, 1998. "Compliance with the 1994 Nonresidential Washington State Energy Code," pp. 4.249-4.259, 1998 ACEEE Summer Study on Energy Efficiency in Buildings, American Council for an Energy-Efficient Economy.

McLain, H., S. Leigh, and J. McDonald, 1994. Analysis of Savings Due to Multiple Energy Retrofits in a Large Office Building, ORNL/CON-363, Oak Ridge National Laboratory, Oak Ridge, TN, May. 
Nadel, S. and K. Keating, 1991. "Engineering Estimates vs. Impact Evaluation Results: How Do They Compare and Why?" Proceedings of the 1991 International Energy Program Evaluation Conference. Chicago, IL, pp. $24-33$.

Nadel, S., L. Rainer, M. Shepard, M. Suozzo, and J. Thorne, 1998. Emerging Energy-Saving Technologies and Practices for the Building Sector, American Council for an Energy-Efficient Economy, Washington, DC.

National Association of State Energy Officials, 2002. Revolving Loan Fund: Texas LoanStar Program.

National Center for Transit Research, 2005. State Average for Private Vehicle Occupancy, Carpool Size and Vehicles Per 100 Workers, University of South Florida, http://www.nctr.usf.edu/clearinghouse/censusavo.htm

National Renewable Energy Laboratory, 1995. Energy-Efficient Lighting, DOE/GO-10095-056, FS141, December.

Nebraska Energy Office, 1997. Dollar and Energy Savings Loan Program, Program Evaluation of Energy Savings, Dollar Savings, Greenhouse Gas Emission Reductions, Economic Benefits, Feb. 14. http://www.state.ne.us/home/NEO/daeslpev.htm

New York State Energy Research and Development Authority, 2001a. Quarterly Report, June 2001, Albany, NY.

New York State Energy Research and Development Authority, 2001b. Commercial/Industrial Performance Program Case Study: Variable-Speed Drive Dairy Farm Project, Albany, New York.

New York State Energy Research and Development Authority, 2003. New York Energy \$mart Program Evaluation Status Report, Albany, NY, May.

Oregon Office of Energy, 2000. Tax Credits and Loans for Energy-Saving Projects, http://www. energy.state.or.us/bus/tax/pgt.htm

Pacific Gas and Electric, 2003a. 2003 Energy Efficiency Programs R.01-08-028 Implementation Plan: Statewide Residential Retrofit Single Family Energy Efficiency Rebate, June.

Pacific Gas and Electric, 2003b. 2003 Energy Efficiency Programs R.01-08-028 Implementation Plan: Statewide Residential Retrofit Multifamily Energy Efficiency Rebate, June.

Pacific Gas and Electric, 2004a. Single Family Home Energy Efficiency Rebate Program, May.

Pacific Gas and Electric, 2004b. Multifamily Energy Efficiency Rebate, May.

Perich-Anderson, J. and L. Dethman, 1994. "How Well is Our Energy Code Working? An Evaluation of the Tacoma, Washington Model Conservation Program," pp. 6.149-6.156. 1994 ACEEE Summer Study on Energy Efficiency in Buildings, American Council for an EnergyEfficient Economy. 
Peters, J.S., and M.R. McRae, 2001. Market Progress Evaluation Report, Architecture + Energy Program, Final Report, Report \#E01-084, Northwest Energy Efficiency Allowance, Portland, Oregon, June.

Reed, J.M., M. O'Drain, and J. Chace, 1999. “Transforming Markets Through Educational Information: A Study of the Pacific Energy Center," 1999 International Energy Program Evaluation Conference, Denver, CO, August 18-20.

Residential Energy Services Network, 2001. Home Energy Ratings: A Primer. http://www. natresnet.org/herseems/HERSPrimer/HP04.htm

Rutgers University, 1999. Industrial Assessment Center Program, Fiscal Year 1999 Annual Report, http://oipea-www.rutgers.edu/

Schweitzer, M. and J. Eisenberg, 2002. Meeting the Challenge: The Prospect of Achieving 30 Percent Savings Through the Weatherization Assistance Program, ORNL/CON-479, Oak Ridge National Laboratory, Oak Ridge, TN, May.

Schweitzer, M., and B. Tonn, 2002. Nonenergy Benefits from the Weatherization Assistance Program: A Summary of Findings from the Recent Literature, ORNL/CON-484. Oak Ridge National Laboratory, Oak Ridge, TN, April.

Schweitzer, M., L.G. Berry, D.W. Jones, and B. E. Tonn, 2003. Estimating Energy and Cost Savings and Emissions Reductions for the State Energy Program Based on Enumeration Indicators Data, ORNL/CON-487. Oak Ridge National Laboratory, Oak Ridge, TN, January.

Skabardonis, A., 2001. "ITS Benefits: The Case of Traffic Signal Control Systems," Paper presented at the Transportation Research Board 2001 Annual Meeting, Washington, DC, Jan. 711.http://www.benefitcost.its.dot.gov/ITS/benecost.nsf/ID/42419C3E5993E9CD852569EA0071 D556

State of California, 2004. Flex Your Power: Agricultural. http://www.fypower.org/agri/index.html

Tools of Change, 2004. Whitney Public School Case Study, www.toolsofchange.com

U.S. Census Bureau, 2002. Census 2000 Summary File 1, Matrices PCT 12 and P13, Washington, DC.

U.S. Census Bureau, 2003. Table 2au. New Privately Owned Housing Units Authorized by State and Region, 2002. http://www.census.gov/const/c40/Table2/tb2u2002.txt

U.S. Department of Agriculture, 2004a. United States Agricultural and Forestry Greenhouse Gas Inventory: 1990-2001. Global Change Program Office, Office of the Chief Economist, USDA, Technical Bulletin No. 1907, March.

U.S. Department of Agriculture, 2004b. 2002Census of Agriculture-United States Data, National Agricultural Statistics Service, http://www.nass.usda.gov/census 
U.S. Department of Energy, 1999. Energy Consumption Characteristics of Commercial Building HVAC Systems, Volume II: Thermal Distribution, Auxiliary Equipment, and Ventilation. Office of Building Technology, State and Community Programs, Washington, DC, October.

U.S. Department of Energy, 2001a. State Energy Program, http:/www.eren.doe.gov/buildings/ state_energy

U.S. Department of Energy, 2001b. GPRA Data Call 2003. Office of Energy Efficiency and Renewable Energy, Washington, DC, September 14.

U.S. Department of Energy, 2002a. FEMP's Energy Cost Calculators. http://www.eren.doe.gov/ femp/procurement/calc-index.html

U.S. Department of Energy, 2002b. Performance Planning Guidance FY 04-08, Draft, Office of Energy Efficiency and Renewable Energy, Washington, DC, May 7.

U.S. Department of Energy, 2002c. Transportation Energy Data Book, Edition 22, Chap. 7, Table 17.

U.S. Department of Energy, 2003a. 2003 Buildings Energy Data Book. Energy Efficiency and Renewable Energy. http://buildingsdatabook.eere.energy.gov

U.S. Department of Energy, 2003b. Commercial Buildings Determinations. Building Energy Codes Program. www.energycodes.gov/implement/determinations_com_exp.sts

U.S. Department of Energy 2003c. State Energy Program Operations Manual. Office of Energy Efficiency and Renewable Energy, January.

U.S. Department of Energy, 2003d. Transportation Energy Data Book, Edition 23. Energy Efficiency and Renewable Energy. http://www-cta.ornl.gov/data/Index.html

U.S. Department of Energy and U.S. Environmental Protection Agency, 2004. Energy Efficiency and Renewable Energy. www.fueleconomy.gov

U.S. Environmental Protection Agency, 2000a. Average Annual Emissions and Fuel Consumption for Passenger Cars and Light Trucks, EPA 420-F-00-013, Office of Transportation and Air Quality, Ann Arbor, MI, April.

U.S. Environmental Protection Agency, 2002b. Procedures Manual for Estimating Emission Reductions for Voluntary Measures and Commuter Choice Incentive Programs, EPA 420-R-00015, Air and Radiation, Washington, DC, October.

U.S. Environmental Protection Agency, 2001. Energy Star Building Manual, Air and Radiation (6202J), October.

U.S. Environmental Protection Agency, 2002. Simple Savings Calculator. http://www.epa.gov/ enrgystar/purchasing/2c_savings_calc.html 
Vine, E.L. 1996. "Residential Building Code Compliance: Implications for Evaluating the Performance of Utility Residential New Construction Programs," Energy, Vol. 21, No. 12, pp.1051-1058.

Vine, E., S. Barata, N. Hall, P. Landry, J.S. Peters, and C. White, 2005. A Review of State Energy Program Performance Metrics, Final Report. Prepared for U.S. Department of Energy, Office of the Weatherization and Intergovernmental Program.

Virginia Department of Transportation, 2000. Traffic Signal Optimization for Tysons Corner Network, Report \#TPE.R7D.03.08.00, March. http://www.benefitcost.its.dot.gov/ITS/benecost. nsf/ID/5526CCA9B17F9309852569610051E2DA

Webber, C.A., R.E. Brown, and J.G. Koomey, 2000. "Savings Estimates for ENERGY STAR Voluntary Labeling Program," Energy Policy 28, 1137-1149.

Whalen, M.V., and T.C. Coburn, 1997. Perspectives on AFVs: 1996 Survey of Drivers of LightDuty Federal Fleet Vehicles, NREL/TP-540-22721, National Renewable Energy Laboratory, Golden, Colorado, September.

Whalen, M., L. Eudy, and T. Coburn, 1999. Perspectives on AFVs: State and City Government Fleet Driver Survey, NREL/TP-540-25929, National Renewable Energy Laboratory, Golden, Colorado, April.

www.fueleconomy.gov [Transportation fuel economy website sponsored by the U.S. Department of Energy and U.S. Environmental Protection Agency] 


\section{ACKNOWLEDGMENTS}

We would like to thank the following people for their important contributions to the State Energy Program evaluation. Joel Eisenberg of Oak Ridge National Laboratory provided valuable guidance and support throughout this project and all the State Energy Program metrics work that preceded it. The National Association of State Energy Officials was an indispensable partner throughout the research effort, providing important information and advice and encouraging the states and territories to submit the necessary data on their SEP activities. Miranda Eady of ORNL undertook the considerable task of organizing and entering all the data submitted by the states. Helpful reviews of a draft report documenting the study were provided by Donald Milsten of NASEO and by Victoria D'Urso and Melissa Madgett of ORNL. In addition, representatives of eight state energy offices reviewed the draft document and sent us valuable comments. They are: Debi Conrad of West Virginia; Ruth Horton of New York; Linda Limback of Minnesota; Chantal Fryer and Janet Lockhart of South Carolina; Tom Martin of Michigan; Carolyn Sullivan of Oklahoma; James P. Taylor of New Hampshire; and Lisa Yoder of Utah. As noted in the body of the report, the Board of Directors of the International Energy Program Evaluation Conference, Inc. performed a peer review of the performance metrics used in the study and submitted many useful comments and suggestions that helped improve the quality of the final document. The individuals who contributed to that review are Edward Vine, Sharyn Barata, Nick Hall, Pierre Landry, Jane S. Peters, and Carol White. Faith Lambert and Ronald Santoro of the U.S. Department of Energy provided valuable input and support throughout the study. Finally, Tracy Bodine at ORNL assembled the draft and final reports. 


\section{APPENDIX A. DEVELOPMENT OF ENERGY-SAVINGS COEFFICIENTS}

ORNL staff developed per-unit savings coefficients for at least one performance metric in each of 17 project areas. Each of these coefficients describes the primary energy savings (expressed in million source BTUs) associated with a specific activity (e.g., the performance of a single energy audit). In most project areas, only a single performance metric was used, although multiple coefficients were typically developed - one for each end-use sector (e.g., residential, commercial, industrial) addressed by state projects. Each of these per-unit savings coefficients was multiplied by the number of activities reported by the states in the relevant project area and end-use sector to calculate total savings. We also generated an estimate of petroleum savings for selected activities in the Alternative Energy area.

For several project areas, multiple performance metrics were developed, savings were calculated for each metric, and the component savings were then combined to yield total savings for that area. For example, in the case of Mass Media, savings were calculated for both the number of materials downloaded from internet websites and the number of printed materials distributed. The savings resulting from each of these distinct activities were summed to get total savings for that project area. In the case of Codes and Standards, the information provided by three separate metrics (name of new code, name of old codes, and percentage of new construction covered by code) was used together to develop a single energy savings estimate.

In two project areas for which multiple metrics were developed (Retrofits and Energy Audits), only one of the metrics was actually used in each state to avoid double-counting savings related to the reported activities. In the Retrofits area, coefficients were developed for use both with number of buildings and number of square feet retrofitted. If a state provided square footage data, that was used to calculate savings because it was expected to yield a more accurate estimate; otherwise, savings were calculated from the number of buildings retrofit. For Audits, stateprovided estimates of savings (in an adjusted form described later in this Appendix) were used if available. Otherwise, square footage served as the basis for our savings calculation. If data were provided for neither of those metrics, we calculated savings from the number of buildings retrofit.

A discussion of how each coefficient was developed—organized by project area, performance metric, and end-use sector-is provided below.

\section{MASS MEDIA}

For Mass Media programs, we used two different metrics: (1) the number of downloads from internet websites of printed materials, and (2) the number of printed materials distributed. Separate energy-savings multipliers were developed for six different end-use sectors (industrial; residential; commercial; institutional; transportation; and agricultural) for each metric. Below, we describe the development of the energy-savings coefficients used with each metric and sector.

\section{Metric 1: Number of downloads from internet websites of printed materials, by sector}

We were able to find almost no quantitative data on the amount of energy savings achieved by Mass Media programs. However, we did acquire information for the Industrial sector on the average energy savings achievable by implementing the measures described in a 
single publication of the type that is typically distributed by energy-efficiency/renewable energy programs. To approximate the savings likely to occur in the Industrial sector, those savings were adjusted downward to reflect the circumstances surrounding a typical Mass Media program that provides downloadable materials (as explained below). We then calculated the savings per Industrial sector download as a proportion of the savings achieved per Industrial sector Technical Assistance contact. That factor was multiplied by the Technical Assistance coefficient in each other sector to get estimated savings per download for those sectors. This is expected to provide reasonable coefficients for those sectors because of the fact that both Technical Assistance and Mass Media efforts work in similar ways (i.e., by presenting information on relevant energyefficiency/renewable energy measures or techniques to potential users).

\section{Industrial}

A rigorous analysis of the tip sheets distributed by DOE's Best Practices program indicated that savings of 98 million source BTUs, on average, could be achieved by implementing the measures described in a single publication (Jones, Tonn, and Martin 2002). We assumed that only $25 \%$ of the materials downloaded contain anything of value to the recipient and are actually read. We further assumed that only $20 \%$ of those who read a relevant publication take some action based on what they learn using findings on the frequency of actions taken in response to several different education and training programs (Reed et.al. 1994, Peters and McRae 2001, Tools of Change 2004) as a surrogate for the frequency of actions stimulated by reading relevant materials that are purposefully sought out and downloaded. Our final assumption is that only $50 \%$ of the measures presented in the downloaded materials are implemented. Accordingly, 98 million source BTUs x $0.25 \times 0.20 \times 0.50$ equals 2.45 million source BTUs, our energy-savings coefficient for Industrial sector downloads.

\section{Residential}

To get the energy-savings coefficient for this sector, we multiplied the Residential Technical Assistance coefficient (2.5 million source BTUs) by 0.025 [the proportion of Mass Media download savings (2.45 million source BTUs) to Technical Assistance savings (98.3 million source BTUs) that was derived from the data available for the Industrial sector]. This gives us a Residential sector energy-savings coefficient of 0.0625 million source BTUs per download.

\section{Commercial}

To get the energy-savings coefficient for this sector, we multiplied the Commercial Technical Assistance coefficient (39.2 million source BTUs) by 0.025 (the Industrial sector proportion of Mass Media download savings to Technical Assistance savings). This gives us a Commercial sector energy-savings coefficient of 0.98 million source BTUs per download.

\section{Institutional}

To get the energy-savings coefficient for this sector, we multiplied the Institutional Technical Assistance coefficient (37.8 million source BTUs) by 0.025 (the Industrial sector proportion of Mass Media download savings to Technical Assistance savings). This gives us an Institutional sector energy-savings coefficient of 0.945 million source BTUs per download. 


\section{Transportation}

To get the energy-savings coefficient for this sector, we multiplied the Transportation Technical Assistance coefficient (10.2 million source BTUs) by 0.025 (the Industrial sector proportion of Mass Media download savings to Technical Assistance savings). This gives us a Transportation sector energy-savings coefficient of 0.255 million source BTUs per download.

\section{Agricultural}

To get the energy-savings coefficient for this sector, we multiplied the Agricultural Technical Assistance coefficient (13.2) by 0.025 (the Industrial sector proportion of Mass Media download savings to Technical Assistance savings). This gives us an Agricultural sector energysavings coefficient of 0.33 million source BTUs per download.

\section{Metric 2: Number of printed materials distributed, by sector}

As previously reported, we obtained information for the Industrial sector on the average energy savings achievable by implementing the measures described in a single publication of the type that is typically distributed by energy-efficiency/renewable energy programs. To approximate the savings likely to occur from the distribution of printed materials, the Industrial sector savings mentioned above were adjusted downward to reflect the circumstances surrounding a report-distribution effort. As shown below, each publication that is distributed is expected to result in substantially lower savings than each downloaded material. We then calculated the savings per printed material distributed in the Industrial sector as a proportion of the savings achieved per Industrial sector Technical Assistance contact. That factor was multiplied by the Technical Assistance coefficient in each other sector to get estimated savings per material distributed in those sectors.

\section{Industrial}

As noted above, a rigorous analysis of the tip sheets distributed by DOE's Best Practices program indicated that savings of 98 million source BTUs, on average, could be achieved by implementing the measures described in a single publication. Because many of the materials distributed are not tailored to the needs of the individual recipients, we assumed that only $10 \%$ of them contain anything of value to the recipient and are actually read. We further assumed that only $1.61 \%$ of those who read a relevant publication take some action based on what they learn, which is the percentage of direct mail recipients who respond by buying something (Direct Marketing Association 2003). Our final assumption is that those who act on the relevant information implement only $50 \%$ of the relevant measures. Accordingly, 98 million source BTUs x 0.10 × 0.0161 x 0.50 equals 0.079 million source BTUs, our energy-savings coefficient for each printed material that is distributed in the Industrial sector .

\section{Residential}

To get the energy-savings coefficient for this sector, we multiplied the Residential Technical Assistance coefficient (2.5 million source BTUs) by 0.0008 [the proportion of Mass Media printed material savings (0.079 million source BTUs) to Technical Assistance savings (98.3 million source BTUs) that was derived from the data available for the Industrial sector]. 
This gives us a Residential sector energy-savings coefficient of 0.002 million source BTUs per printed material distributed.

\section{Commercial}

To get the energy-savings coefficient for this sector, we multiplied the Commercial Technical Assistance coefficient (39.2 million source BTUs) by 0.0008 (the Industrial sector proportion of Mass Media printed material savings to Technical Assistance savings). This gives us a Commercial sector energy-savings coefficient of 0.031 million source BTUs per printed material distributed.

\section{Institutional}

To get the energy-savings coefficient for this sector, we multiplied the Institutional Technical Assistance coefficient (37.8 million source BTUs) by 0.0008 (the Industrial sector proportion of Mass Media printed material savings to Technical Assistance savings). This gives us an Institutional sector energy-savings coefficient of 0.030 million source BTUs per printed material distributed.

\section{Transportation}

To get the energy-savings coefficient for this sector, we multiplied the Transportation Technical Assistance coefficient (10.2 million source BTUs) by 0.0008 (the Industrial sector proportion of Mass Media printed material savings to Technical Assistance savings). This gives us a Transportation sector energy-savings coefficient of 0.008 million source BTUs per printed material distributed.

\section{Agricultural}

To get the energy-savings coefficient for this sector, we multiplied the Agricultural Technical Assistance coefficient (13.2 million source BTUs) by 0.0008 (the Industrial sector proportion of Mass Media printed material savings to Technical Assistance savings). This gives us an Agricultural sector energy-savings coefficient of 0.011 million source BTUs per printed material distributed.

\section{SCHOOL EDUCATION PROGRAMS}

\section{Metric: Number of K-12 students taught with instructional units developed or distributed by program}

School education programs lead to energy savings when students are able to influence their households to take the energy-conserving action(s) that they were taught. A simple formula for representing this is as follows: Energy savings per student taught $=$ the proportion of students who influence their families to take action times the average savings associated with the action(s) taken.

We obtained data on the proportion of students who influence their families to take action from a case study of a recycling education program in a Toronto, Ontario elementary school 
(Tools of Change, 2004). A survey distributed to the parents indicated that $25 \%$ of the students' families made substantial changes in their recycling habits as a result of the education program. To be conservative, we divided the $25 \%$ figure in half to reflect the fact that the Toronto program was designed to directly involve parents in their childrens' activities, while many energy education programs may not do so. According, we used 0.125 to represent the proportion of students who typically influence their families to take action.

The average savings associated with the action(s) taken come from a recent ORNL study that examined the energy savings associated with a large number of possible home weatherization activities (Schweitzer and Eisenberg 2002). We selected a set of three common low-cost/no-cost measures that could easily be taught to school children and explained by them to their parents or guardians. They are: reset water heater thermostat; install low-flow showerhead and insulate water heater pipes; and install compact fluorescent light bulbs. The average annual savings associated with those measures are 8.6 million source BTUS. Because students are likely to be taught about many other higher-savings measures (like weather-proofing, installing programmable thermostats, and purchasing Energy Star appliances) choosing these three measures seems conservative.

Multiplying the proportion of students who influence their families to take action (0.125) by the average savings associated with the actions taken ( 8.6 million source BTUs) yields an energy-savings coefficient of 1.1 million source BTUs per student taught.

\section{WORKSHOPS AND TRAINING}

\section{Metric: Number of people attending workshops, by sector}

Energy savings resulting from training workshops were estimated separately for training involving the following six end-use sectors.

\section{Residential}

Our approach to developing a residential sector energy-savings multiplier was to select a package of four common energy conservation measures that could easily be taught in workshops and training sessions: air infiltration sealing; re-setting water heater thermostats; attic insulation; and compact flourescent bulbs. Based on past work by ORNL (Schweitzer and Eisenberg, 2002), we calculated that average annual savings per house for these four measures, amounted to 28.7 million source BTUs. We assumed an installation rate of 0.20 , to reflect the findings from three recent studies indicating that roughly $20 \%$ of those attending workshops and similar types of training or educational sessions actually change their behavior in the intended manner as a result of their experience (Reed et al. 1999; Peters and McRae 2001; Tools of Change 2004). Census data (U.S. Census Bureau 1997) indicate that the average residential construction firm builds an average of eight new homes per year. Through phone calls to a number of state energy offices, we collected information on workshop attendance indicating that about one fourth of the trainees are home builders and three fourths are home owners and renters. Thus, using the conservative assumption that a residential retrofitter will work on approximately half the mean number of homes constructed annually by firms engaged in new construction, the typical attendee is assumed to influence 1.75 homes [(1/4 x 4$)+(3 / 4 \times 1)]$. Therefore our multiplier is 28.7 million source BTUs per house $\mathrm{x} 0.20 \times 1.75$, which is equal to 10.0 million source BTUs per workshop 
participant in the residential sector.

\section{Commercial}

From the 1999 Commercial Building Energy Consumption Survey (CBECS) published by the Energy Information Administration (EIA 2002a), we (1) identified the amount of primary energy used by all commercial sector buildings (11,987 trillion source BTUs); (2) calculated the average amount of primary energy used per building (2,574 million source BTUs); and (3) determined the average percentage of primary energy used for HVAC $(47.0 \%)$ and lighting (18.0\%). From these data, we calculated that the average commercial building uses 1,210 million source BTUs for HVAC purposes and 463 million source BTUs for lighting.

From McLain et al. (1994) and Abraham and MacDonald (1995), we obtained estimates of percent energy savings possible from HVAC and lighting retrofits in large and small office buildings. Because the buildings examined in those documents were selected for their unusually high savings opportunities, the reported savings (for HVAC, $48.6 \%$ in large buildings and $62.3 \%$ in small buildings; for lighting, $36.1 \%$ in large buildings and $31.3 \%$ in small buildings) were divided in half to better represent the potential savings achievable in more typical office buildings. Those savings numbers were then multiplied by an installation rate of 0.20 , to reflect the finding noted above that roughly $20 \%$ of workshop attendees respond to workshop teachings by changing their behavior in the desired manner. For the small commercial buildings described in Abraham and MacDonald, potential savings were also multiplied by a realization rate of 0.9 because the numbers presented in the report came from projections rather than actual measurement. The adjusted numbers thus calculated for large and small buildings were averaged to yield estimated savings of $5.25 \%$ for HVAC measures and $3.2 \%$ for lighting measures.

The average commercial building consumption of 1,210 million source BTUs for HVAC purposes was multiplied by the 5.25 percent savings number to give us average annual savings of 63.5 million source BTUs per building. For lighting, the average consumption of 463 million source BTUs was multiplied by savings of 3.2 percent to yield average annual savings of 14.8 million source BTUs per building.

We assumed that those attending the workshops and training sessions represented a mix of the professions and businesses involved in the design, construction, and operation of commercial buildings, including architects, engineers, owners, and facility managers. From Reed et al. (1999), we obtained estimates of the number of buildings affected by each person attending a training session. The Reed study examined a program that served a great variety of building professions and reported a range of from one to over ten structures influenced annually by each participant. We multiplied the energy savings per building by the median number of buildings influenced annually by each participant (four) to obtain the energy savings per trainee for lighting training and HVAC training, and then calculated a simple average of the two.

Table A.1 reports the estimated savings per building and per trainee for each type of training and also gives average savings for the two. For our multiplier, we used the mean savings for the two types of training, which has a value of 156.8 million source BTUs per workshop attendee. 
Table A.1. Estimated energy savings from commercial sector training programs

\begin{tabular}{cccc}
\hline & $\begin{array}{c}\text { Focus of } \\
\text { training }\end{array}$ & $\begin{array}{c}\text { Million source } \\
\text { BTUs/bldg }\end{array}$ & $\begin{array}{c}\text { Million source BTUs/trainee, four } \\
\text { buildings influenced }\end{array}$ \\
\hline $\begin{array}{c}\text { All } \\
\text { commercial } \\
\text { buildings }\end{array}$ & HVAC & 63.5 & 254.0 \\
\hline & lighting & 14.8 & 59.2 \\
\hline
\end{tabular}

\section{Industrial}

Our work to attribute energy savings to workshops and training in the industrial sector is based on ORNL's energy savings metrics research for DOE's Best Practices Program (Jones et al. 2002). As part of that project, we estimated energy savings attributable to Best Practices workshops and training activities. We assume that industrial energy-efficiency workshops and training offered by the SEP are equivalent to those offered by Best Practices.

In FY2002, Best Practices offered workshops and training in five technical areas: pumps; process heat; steam; compressed air; and motors. We used as an energy savings baseline the energy savings estimated by Best Practices Program Collaborative Targeted Assessments (CTAs). A CTA involves having energy-efficiency experts examine a plant to identify the most obvious energy-savings opportunities. We calculated average energy savings per attendee using actual reports on those who participated in workshop and training sessions. Next, as noted above, we adjusted this average by 0.20 to reflect the likely installation rate. By following these steps, we came up with an industrial multiplier of 393.2 million source BTUs per attendee.

\section{Institutional}

Our approach to developing a workshops and training multiplier for the institutional sector was to focus on four key applications: chillers; lighting; variable speed drives; and energy management systems. From the literature, we estimated that activities related to saving energy for these four areas would result in energy savings of $20 \%$ for chillers, $48 \%$ for lighting, $30 \%$ for variable speed drives, and 10\% overall for energy management systems (U.S. Environmental Protection Agency 2001; Energy Design Resources 2004). CBECS indicates that the average energy use per building is 521 million source BTUs for chillers, 463 million source BTUs for lighting, and roughly 2500 million source BTUs for all purposes. We estimated that average energy use for pumps and fans that could utilize variable speed drives is approximately 595 million source BTUs (U.S. Department of Energy 1999, Energy Information Administration 2002a). We multiplied each of the energy use numbers given above by the expected savings factor in that area (i.e., 521 million source BTUs for chillers x $0.20 ; 463$ million source BTUs for lighting x 0.48 ; 595 million source BTUs for pumps and fans by 0.30 ; and 2500 million source BTUs building-wide $\mathrm{x} 0.10$ of energy management system savings). We then summed the resulting energy savings and divided by four, based on the assumption that a workshop or training session would cover only one of these areas. To account for the installation rate, we multiplied this average savings number by 0.20 . Then we multiplied that result by four to account for our expectation that each participant would influence energy savings in four facilities (Reed et.al. 1999). The resulting energy-savings coefficient for the Institutional sector is 151.0 million source BTUs. 


\section{Transportation}

We considered two types of training workshops directed at vehicles: maintenance and energy-efficient driving. For both types of vehicle training, we used a combined engineering savings/behavioral discount parameter of 0.106 , from Greene (1986). In other words, both the improved maintenance derived from the maintenance training and the better driving from the driver training were expected to improve fuel mileage by 10.6 percent. The savings parameter of 0.106 was multiplied by annual per-vehicle fuel consumption, which was calculated by dividing the assumed distance driven each year by a single vehicle (a weighted average of 11,528 miles for passenger cars and light trucks) by the miles per gallon (a weighted average of 20.4). Both the number of miles driven and the average miles per gallon were taken from the latest version of the Transportation Energy Data Book (U.S. DOE 2003d).

The calculation $(0.106$ in savings $) \times(11,528$ miles/year $) / 20.4 \mathrm{mpg}$ yields 59.9 gallons per year fuel savings per vehicle. Each gallon of gasoline is equivalent to 123,905 BTUs (U.S.DOE $2002 \mathrm{~b}$ ). For driver training, we assumed one vehicle per workshop attendee, yielding savings of 7.4 million source BTUs per attendee. For maintenance training, we assumed 10 vehicles per workshop attendee, which yields savings of 74.0 million BTUs per attendee. For our energy savings coefficient, we used a simple mean of the two numbers, which is 40.7 million source BTUs per workshop attendee.

\section{Agricultural}

To develop a multiplier for the Agricultural sector, we collected data on the energy savings achieved by three common energy efficiency measures: variable speed drives for milking equipment; repairs and upgrades to irrigation pumps; and dairy farm refrigeration improvements. From the available literature (NYSERDA 2001b; Equipoise Consulting, Inc. 2004; EnSave Energy Performance, Inc. 2002), we found that the combined savings for these three measures average 792 million source BTUs per year. We divided that combined savings number by three, based on the assumption that the typical workshop or training session would address only one of those areas. To account for the installation rate, we multiplied the average savings number by 0.20 . Because the vast majority of U.S. farms are owned by a family or partnership, we assumed that the average workshop participant would represent a single farm.

Thus, our multiplier is the product of 264 million source BTUs (the average of the three measures presented above) times 0.20 (the installation rate) times one (the number of farms influenced by each participant). This gives us an energy-savings coefficient of 52.8 million source BTUs per workshop attendee.

\section{RETROFITS}

We report energy-savings estimates for retrofits in residential and commercial structures, schools, health care facilities, government buildings, and industrial applications. We use two metrics for retrofits: the number of buildings retrofitted and the square footage retrofitted. We describe the development of the energy-savings coefficients used with each metric separately. 


\section{Metric 1: Number of buildings retrofit, by sector}

\section{Residential}

We obtained primary energy savings per house from residential retrofits for four regions of the country from Schweitzer and Eisenberg (2002). These savings estimates were for actions that could be taken by the Weatherization Assistance Program (WAP) in typical houses at costs ranging from about $\$ 1200$ to almost $\$ 2000$ per house (without program overhead), depending on the region. The projected savings achievable in each region are as follows:

- Northeast: 43.1 million source BTUs/house

- South: $\quad 40.0$ million source BTUs/house

- Midwest: 66.8 million source BTUs/house

- West: 23.6 million source BTUs/house

We used an unweighted, nationwide average energy savings of 43.4 million source BTUs per house for the coefficient value of a residential retrofit.

\section{Commercial}

From the 1999 Commercial Building Energy Consumption Survey (EIA 2002a), we used 14,500 square feet and 2574.0 million source BTUs as the average size and annual energy use of a commercial building, respectively. From Greely et.al. (1990) and Coates (1995), we obtained an average of 18.8 percent savings in retrofits for commercial buildings. The product of the energy use and savings figures yields a coefficient of 483.9 million source BTUs of energy savings per commercial retrofit project.

\section{Schools}

The 1999 CBECS reports the average size of schools as 26,400 square feet, and Greely et al. (1990) cite the measured energy savings of the retrofits in schools as 0.016 million source BTUs per square foot of floor space. The product of these two numbers is 422.4 million source BTUs per retrofit project.

\section{Health Care}

According to the 1999 CBECs, the average size of a health care facility (inpatient and outpatient combined) is 23,000 square feet. Lew and Wang (1998) report the annual energy savings per retrofit in hospitals as 0.041 million source BTUs per square foot and we use that number to represent the savings possible in all health care facilities. The product of those two numbers gives an energy-savings coefficient value of 943.0 million source BTUs per retrofit project.

\section{State Government}

Estimates for energy savings associated with retrofitting state buildings were derived from energy savings estimates for federal building retrofits. DOE's Federal Energy Management Program (FEMP) funds energy assessments of federal buildings through its SAVEnergy program. One hundred and ninety-seven non-energy-intensive buildings were identified for analysis in the 
FEMP database called FEMP Central (FEMP 2004b). The average annual energy savings per building was calculated to be 1,607 million source BTUs per year.

\section{Industrial}

Rutgers University (1999) publishes annual reports on DOE's Industrial Assessment Center (IAC) Program. Table 18 of that document provides data on average implemented energy and cost savings per assessment (or audit) for that year. The average implemented energy savings in 1999 was 4,044 million source BTUs per assessment. Based on program experience, we know that audited establishments typically only implement measures that result in about one-half of the possible energy savings described in the assessment report, primarily because of the cost involved. Thus, the amount of energy that could be saved by performing a complete retrofit is 8,088 million source BTUs per industrial establishment.

\section{Metric 2: Floor space of buildings retrofit, by sector}

\section{Residential}

We use an average residence size of 1707 square feet, which is the average heated square footage for all residential units in the U.S. from the 2001 Residential Energy Consumption Survey (EIA 2003b). Dividing the average energy savings per building described under the first metric for this project area (43.4 million source BTUs) by this average house size, we obtain a coefficient value of 0.025 million source BTUs per square foot.

\section{Commercial}

We divided the 483.9 million source BTUs of energy savings per commercial building by the 14,500 square footage figure for the average commercial building to obtain a coefficient value of 0.033 million source BTUs per square foot.

\section{Education}

As noted above, Greely et.al. (1990) report that school retrofits yield an average energy savings of 0.016 million source BTUs per square foot of floor space.

\section{Health Care}

As note above, Lew and Wang (1998) report that retrofits in hospitals result in average savings of 0.041 million source BTUs per square foot.

\section{State Government}

As noted above, using DOE's FEMP Central database, we estimated that annual energy savings per government building retrofit was 1,607 million source BTUs. Also from FEMP Central, we calculated the average size of the 197 buildings in our sample: 32,998 sq. ft. Dividing the first number by the second yields a multiplier for annual energy savings for state government buildings of 0.0487 million source BTUs per square foot retrofit. 


\section{Industrial}

As noted above, the estimated energy savings per industrial retrofit is 8,088 million source BTUs. According to the Energy Information Administration's Manufacturing Energy Consumption Survey (2000), the average size of an industrial establishment is 71,257 square feet. Dividing the energy-savings number by the size of the average industrial establishment produces our multiplier of 0.1135 million source BTUs per square foot retrofit.

\section{ENERGY AUDITS}

We estimated energy savings from audits for the residential, commercial, industrial, and institutional, sectors. We assume that those receiving audits are not also receiving SEP financial assistance to install the measures recommended in the audits. Accordingly, they are expected to install fewer measures than would be involved in a full building retrofit, both because of the costs involved and because some measures may not be considered desirable or appropriate for a variety of reasons. Ideally, the responding states would not report both audits and retrofits performed on the same structures. However, it is possible that such double-counting might have occurred in some instances (despite warnings in the spreadsheet instructions), which would result in some over-statement of savings. We use three metrics for audits: the number of buildings audited, the floor space audited, and projected energy savings.

\section{Metric 1: Number of audits performed, by sector}

\section{Residential}

The per-unit energy savings estimate for residential retrofits listed previously (43.4 million source BTUs per project) provides the base for our estimate of savings associated with energy audits in the residential sector. We applied an adjustment factor of 0.50 to the retrofit number, based on the conservative assumption that only half of the recommended measures would be installed. This yields a savings coefficient of 21.7 million source BTUs per audit project.

\section{Commercial}

The per-unit savings estimate for commercial retrofits listed previously (483.9 million source BTUs per project) provides the base for our estimate of savings associated with energy audits in the commercial sector. We applied an adjustment factor of 0.50 to the retrofit number, based on the conservative assumption that only half of the recommended measures would be installed. This yields a savings coefficient of 242.0 million source BTUs per audit project.

\section{Industrial}

For our estimate of expected savings per industrial audit, we used the figure of 4,044 million source BTUs from the IAC evaluation. That number represents the average savings achieved by participating firms as a result of taking various actions recommended in the assessments of energy-saving opportunities performed under the IAC program. 


\section{Institutional}

The per-unit savings estimates for schools, health care facilities, and state government buildings presented in the Retrofits section (above) provide the basis for the institutional audit savings multipliers used in this study. We calculated the weighted average of retrofit savings per building for these three sectors, based on the proportion of all Institutional sector space reported by each building type. Those calculations yielded a weighted average of 895.5 million source BTUs per Institutional building retrofit. We applied an adjustment factor of 0.50 to this weighted average, based on the conservative assumption that only half of the recommended measures would be installed. This yields a savings coefficient of 447.8 million source BTUs per audit project in the institutional sector.

\section{Metric 2: Floor space audited, by sector}

\section{Residential}

We divided the 21.7 million source BTUs saved per audit by the 1707 square feet of the average dwelling unit to obtain 0.0127 million source BTUs per square foot.

\section{Commercial}

We divided the 242 million source BTUs of energy savings per commercial audit by the 14,500 square feet of the average sized commercial building to obtain 0.0167 million source BTUs per square foot.

\section{Industrial}

We divided the 4,044 million source BTU savings per industrial audit by the 71,257 square feet of the average industrial establishment (EIA 2000) to obtain our energy-savings coefficient of 0.057 million source BTUs per square foot.

\section{Institutional}

The per-square foot savings estimates for schools, health care facilities, and state government buildings presented in the Retrofits section (above) provide the basis for the institutional audit savings multipliers used in this study. We calculated the weighted average of retrofit savings per square foot for these three sectors to be 0.0309 million source BTUs. We applied an adjustment factor of 0.50 to this weighted average, based on the conservative assumption that only half of the recommended measures would be installed. This yields a savings coefficient of 0.0155 million source BTUs per square foot audited in the institutional sector.

\section{Metric 3: Projected energy savings, by sector}

Where the states provided their own estimates of audit-related energy savings, those numbers were used, after adjusting them downward to reflect the expectation that only half of the recommended measures would be installed and that only a portion of the projected savings (60 percent in the residential sector and 90 percent in all other sectors) actually would be realized by the measures taken. The realization rates used here are based on the combined findings from a number of studies comparing predicted and actual energy savings (Nadel and Keating 1991; 
Barakat and Chamberlin, Inc., 1995; Brown and Mihlmeister 1995; and Gettings et.al. 1998). Based on the above expectations, we multiplied state-projected savings by adjustment factors of $0.3(0.50 \times 0.60)$ in the residential sector and $0.45(0.50 \times 0.90)$ in all other sectors.

\section{PROCUREMENT OF ENERGY-EFFICIENT PRODUCTS}

We estimated savings from the procurement of more energy-efficient vehicles, office equipment, HVAC equipment, streetlights, and exit signs by government agencies.

\section{Metric: Number of units purchased, by type}

\section{Vehicles}

This analysis considered the purchase of two different classes of vehicles, mid-size automobiles and standard pick-up trucks, using mileage figures provided by the Fueleconomy.gov website maintained by DOE and the U.S. Environmental Protection Agency (EPA) (2004). Based on national purchasing patterns, we estimated that $47.1 \%$ of vehicles purchased by governments are automobiles and 52.9\% are trucks. Based on an average of 11,766 miles driven per automobile per year (U.S. DOE 2003d), we estimated that the energy savings from an energy-efficient automobile (Chevrolet Malibu, 4 cyl., 2.2L, automatic) compared to a standard automobile (Mercury Sable, 6 cyl., 3L, 2-valve, automatic) would be 115 gallons per year. We estimated that the energy savings of an energy-efficient truck (Ford Ranger, 2WD, 4 cyl., 2.3L, automatic) compared to a standard truck (Ford Ranger, 2WD, 6 cyl., 4L, automatic), assuming they are driven the national average of 11,140 miles per year, would be 122 gallons per year. The weighted savings would be 119 gallons per year per energy-efficient vehicle purchased. Assuming one gallon of gasoline is equivalent to 123,905 BTUs (U.S. DOE 2002b), our multiplier is 14.7 million source BTUs per energy-efficient vehicle purchased.

\section{Office equipment}

Information on energy savings from energy-efficient (ENERGY STAR) office equipment was taken from the ENERGY STAR website (2000). We used an unweighted average kWh savings for computer and monitor, scanner, printer, fax machine, and copier. Converting that average to source energy yields an average of 2.56 million source BTUs per unit of office equipment.

\section{HVAC equipment}

We assumed that commercial buildings of four general types (education, office, public assembly, and public order and safety) would primarily be affected by government procurement programs. According to the 1999 CBECs, the average annual energy consumption for a single building of those types is 3,281 million source BTUs. For all commercial building types, $47.0 \%$ of total energy consumption is for HVAC purposes. Applying that percentage to the average energy use for the four building types of interest, we calculate that 1,542 million source BTUs are used for HVAC purposes. Using data from a recent study of emerging technologies (Nadel et.al. 1998) and from web-based savings calculations provided by ENERGYSTAR (U.S. EPA 2002) and the Federal Energy Management Program (U.S. DOE 2002a), we estimated that savings from the procurement of highly efficient HVAC equipment would amount to $20 \%$ of current per- 
building consumption for HVAC purposes, or 308.4 million source BTUs annually per building HVAC system purchased.

\section{Streetlights}

State and local governments buy streetlights to replace existing lights and to install new ones where none previously existed. We assume that the standard energy-efficient streetlight is a high pressure sodium (HPS) lamp. We also assume that the old units that are replaced are mercury vapor lamps. Replacing the old mercury vapor lamps with HPS lamps yields an energy savings of $600 \mathrm{kWh}$ per year (National Renewable Energy Laboratory 1995). When new lights are installed, we compare the energy consumption of higher-efficiency HPS lamps with the consumption of less-efficient HPS lamps, which yields a savings of $100 \mathrm{kWh}$ per year. Taking a simple average of the energy savings in these two situations yields an energy savings of $350 \mathrm{kWh}$ per streetlight, which converts to 3.8 million source BTUs.

\section{Exit Signs}

According to the Federal Energy Management Program (2004a), the recommended technology for exit signs (compact fluorescent lamps) provides an annual energy savings of 262 $\mathrm{kWh}$ over the base model exit sign (which uses incandescent lamps). Using the conversion factor of $1 \mathrm{kWh}=0.010883$ million source BTUs, we get an annual energy savings of 2.85 million source BTUs. We have rounded this up to 2.9 million source BTUs for our energy-savings multiplier.

\section{TECHNICAL ASSISTANCE}

\section{Metric: Number of contacts in which energy efficiency or renewable energy measures were recommended, by sector}

The type of information given to program clients through technical assistance programs is generally similar to that provided by workshops and training sessions, but technical assistance contacts typically involve a much shorter amount of time and less hands-on instruction and personal interaction. In addition, the subject matter addressed in technical assistance contacts tends to be more limited and focused. Accordingly, the savings coefficients described under Workshops/Training provide a good starting point for calculating Technical Assistance coefficients, but they need to be adjusted downward to reflect the important differences between the two types of programs.

To start, the amount of savings achieved by participants in workshops and training sessions should be cut in half, based on the assumption that fewer measures could be taught in the reduced amount of time involved in most technical assistance contacts. In addition, savings should be cut in half again to reflect the likelihood that the implementation rate (that is, the frequency with which clients actually implement the measures explained to them) would be substantially lower than with workshops and training sessions because the less intensive nature of the technical assistance contact and the limited amount of personal interaction would provide less detailed instruction and would be less motivational. When the 0.5 factor for fewer measures and the 0.5 factor for reduced implementation are multiplied by each other, we get an adjustment factor of 0.25 . In other words, the savings achieved by technical assistance contacts are expected 
to be approximately one-fourth of those associated with workshops and training sessions for the same sector.

The same adjustment factor is considered appropriate for all sectors served by technical assistance programs, because the important differences between technical assistance efforts and workshops/training sessions discussed above are basically the same for all sectors. Accordingly, the Workshops/Training energy-savings coefficient for each end-use sector was multiplied by 0.25 to yield the following Technical Assistance coefficients:

- Residential: 2.5 million source BTUs per contact

- Commercial: 39.2 million source BTUs per contact

- Industrial: 98.3 million source BTUs per contact

- Institutional: 37.8 million source BTUs per contact

- Transportation: 10.2 million source BTUs per contact

- Agricultural: 13.2 million source BTUs per contact

\section{LOANS AND GRANTS}

Energy-savings coefficients were calculated separately for loan and grant programs.

\section{$\underline{\text { Loan Programs }}$}

Metric: Monetary value of loans given, by sector

We were able to find defensible study results on the amount of loans provided and estimated energy savings associated with those loans for the following three programs:

- Oregon Low-Interest Loan Program: covers residential, commercial, institutional and industrial sectors. Estimated annual energy savings were 0.0206 million source BTUs per dollar loaned (Estes 2004).

- Texas LoanStar Program: covers only institutional sector, but results are expected to be similar for the commercial and industrial sectors because of the nature of the measures covered. Estimated annual energy savings were 0.0149 million source BTUs per dollar loaned (NASEO 2002).

- Nebraska Dollar and Energy Savings Loan Program: covers primarily residential sector but also addresses small commercial and some agricultural sector measures. Estimated annual energy savings were 0.009 million source BTUs per dollar loaned (Nebraska Energy Office 1997).

\section{Residential}

Simple average of the Oregon and Nebraska programs: 0.0148 million source BTUs per dollar loaned.

\section{Commercial}

Simple average of the Oregon, Texas, and Nebraska programs: 0.0148 million source BTUs per dollar loaned. 


\section{Industrial}

Simple average of the Oregon, and Texas programs: 0.0178 million source BTUs per dollar loaned.

\section{Institutional}

Simple average of the Oregon, and Texas programs: 0.0178 million source BTUs per dollar loaned.

\section{Agricultural}

This multiplier is based on the agricultural grant coefficient presented below, because no studies could be found on agricultural loan programs. The grant coefficient was multiplied by an adjustment factor of 0.6738 (the average ratio of loan to grant coefficients in all other sectors combined) to yield an energy-savings coefficient of 0.0161 million source BTUs per dollar loaned.

\section{Grants Programs}

\section{Metric: Monetary value of grants given, by sector}

We were able to find defensible study results on the amount of grants provided and energy savings associated with those grants for the following five programs:

- Illinois Energy Efficient Affordable Housing Program: covers residential sector (single family and multi-family) only. Estimated annual energy savings were 0.0145 million source BTUs per dollar granted (Illinois Department of Commerce and Economic Opportunity 2003).

- California Grants: covers only institutional sector, but results are assumed applicable to commercial and industrial sectors because of the nature of the measures covered. Estimated annual energy savings were 0.0108 million source BTUs per dollar granted (Building Systems Engineering and Building Systems Management 2001).

- Louisiana Institutional Conservation Program: covers only institutional sector but results are assumed applicable to commercial and industrial sectors. Estimated annual energy savings were 0.0494 million source BTUs per dollar granted (Louisiana Department of Natural Resources 2001).

- Wisconsin Farm Save Energy Project: covers only the agricultural sector. Estimated annual energy savings were 0.0084 million source BTUs per dollar granted.

- New York State Variable Speed Drive Program: covers only the agricultural sector. Estimated annual energy savings were 0.0337 million source BTUs per dollar granted.

\section{Residential}

We used as our multiplier the result from the Illinois program: 0.0145 million source BTUs per dollar granted.

\section{Commercial}

Simple average of the California and Louisiana programs: 0.0301 million source BTUs 
per dollar granted.

\section{Industrial}

Simple average of the California and Louisiana programs: 0.0301 million source BTUs per dollar granted.

\section{Institutional}

Simple average of the California and Louisiana programs: 0.0301 million source BTUs per dollar granted.

\section{Agricultural}

Simple average of the Wisconsin and New York programs: 0.02105 million source BTUs per dollar granted.

\section{CODES AND STANDARDS}

We collected data on three separate metrics related to building codes: (1) Name of new energy-efficiency building code adopted; (2) Name of old energy-efficiency building code replaced; and (3) Percentage of new construction in state covered by the new code. None of these three metrics, by itself, provides enough information to allow energy savings to be estimated. Rather, the information provided by the states on all three metrics combined was needed to calculate energy savings achieved by code activity. Accordingly, the following discussion will discuss the three metrics together. It should be noted that information also was requested on a fourth metric: Percentage of new appliances covered by mandatory standards. The data provided in response to that item were to be used to calculate savings resulting from the adoption of mandatory state-level appliance standards. However, no states reported engaging in such activity, so a discussion of that metric and its associated multiplier is unnecessary.

The responding states reported adopting, and replacing, a very large number of different codes. Some of them were model codes used by many states around the country (e.g., 1995 Model Energy Code, 2000 International Energy Conservation Code) while others were statespecific codes. Fortunately, each of the state-specific codes was largely similar to one of the model codes and several of the model codes varied minimally from each other in terms of the energy consumption of buildings constructed under their requirements. Accordingly, the number of distinct codes that had to be considered could be reduced to a relatively small number. In states with their own customized codes, officials were interviewed and asked which of the model codes most closely resembled their own state requirements. Information on similarities among the various model codes was provided by building codes experts at Pacific Northwest National Laboratory (Lucas 2004; Halverson 2004).

Once the number of codes used by the various states and territories was reduced to a manageable number by lumping together all codes that were largely similar, we developed estimates of the savings that could be achieved by going from each code (or set of codes) to the next. Commercial codes, which also can be applied to construction in the institutional and industrial sectors, were considered separately from residential codes. 
In the residential sector, our sources indicated that a house built to the 1992 Model Energy Code (MEC) specifications used nearly 17\% less energy for space heating and cooling than a house built to earlier standards. Homes that met the 1993 MEC requirements used 2\% less energy than homes built according to the 1992 MEC; going from the 1993 MEC to the 1995 MEC saved 1\%; and going from the 1995 MEC to the 1998, 2000, or 2003 International Energy Efficiency Code (IEEC) saved roughly another 1\% (Lucas 2002; Lucas 2004).

For commercial and other non-residential structures, there are standards established by the American Society of Heating, Refrigerating and Air Conditioning Engineers (ASHRAE), which the model building codes typically adopt by reference. Our sources indicated that going from the ASHRAE 90A-1980 code (or any of the model energy codes that use its requirements) to the ASHRAE 90.1-1989 standard results in whole-building energy savings of about $13 \%$. (Hadley and Halverson 1993) Replacing the ASHRAE 90.1-1989 standard with the IECC 2000 model code achieves savings of about 3\%, and going from IECC 2000 standards to the ASHRAE 90.1-1999 standard saves about another 3\% (U.S. DOE 2003b). Replacing ASHRAE 90.1-1999 with ASHRAE 90.1-2004 achieves an additional 6\% of whole-building savings (Halverson 2004).

Next, we estimated average energy use per building. For the residential sector, using information contained in the 2001 Residential Energy Consumption Survey (EIA 2003b) and the 2003 Buildings Energy Databook (U.S. DOE 2003a), we calculated that the average amount of energy used annually for space heating and cooling was 72.02 million source BTUs per dwelling. For the commercial sector, data contained in the 1999 Commercial Buildings Energy Consumption Survey (EIA 2002) indicate that the average new commercial structure uses 3,538 million source BTUs per year.

Average annual energy use per building was then multiplied by the savings percentages described earlier to show the energy savings (in million source BTUs) that could be achieved in an average structure by replacing one energy-efficiency building code with a newer one. These calculations were performed separately for residential and commercial codes. Then, the resulting savings numbers were adjusted by a code compliance factor of 0.85 , to reflect the fact that actual energy savings tend to be less than what could theoretically be achieved because many builders do not completely follow all code requirements, especially in the first few years after a new code is adopted. The adjustment factor used here was taken from a number of studies of code compliance (Madison and Baylon 1998; Perich-Anderson and Dethman 1994; Vine 1996).

Once the adjusted per-building savings numbers were calculated, we took data from the 2003 Buildings Energy Databook (U.S. DOE 2003a) and the 1999 Commercial Buildings Energy Consumption Survey (EIA 2002) on the number of buildings constructed. These sources indicated that 1,648,000 residential dwellings were built in 2002 and that an average of 69,000 commercial buildings were constructed each year between 1990 and 1999. The number of buildings was then multiplied by the adjusted per-unit savings numbers to calculate the hypothetical savings that would be achieved nationwide if all the buildings in the country were built according to one particular code as opposed to another. For instance, in the residential sector, if all the houses built in 2002 were constructed according to the 1998 IECC instead of the 1992 MEC, the energy savings would amount to 3.296 trillion BTUs. If all the commercial structures followed ASHRAE 90.1-1999 instead of ASHRAE 90.1-1989, savings of 10.654 trillion source BTUs would be achieved. 
For each state that replaced one particular code with another, the theoretical national savings (described above) were noted. Then the amount saved in that state alone was calculated by multiplying the national number by (1) the proportion of state buildings covered by the code (which was reported by each state as part of its metrics data) and (2) a unique coefficient representing the proportion of total U.S. construction that occurred in that state.

For the residential sector, the number of 2002 building permits issued in each state is available from the U.S. Census Bureau (2003), so it is a simple matter to calculate the proportion of overall residential construction that took place in each state. For the commercial sector, stateby-state construction numbers are not available, but there are data on commercial construction for each of the nine multi-state census divisions for the 10 year period of 1990-1999 (EIA 2002a). We calculated the proportion of total U.S. commercial construction that occurred in each census division during that period and compared it to two other statistics: the proportion of total U.S. residential construction that occurred in that division (U.S. Census Bureau 2003) and the proportion of total U.S. population residing in that region (U.S. Census Bureau 2002). For each census division, we determined which of the latter two statistics was closest to the proportion of total commercial construction occurring there, and used that factor as a surrogate for commercial construction. This was done because state-by-state numbers are available for both population and residential construction but not for commercial construction.

As an example, we determined that $26.5 \%$ of total national commercial construction occurred in the South Atlantic region and that $28.5 \%$ of residential construction took place there, but that only $18.4 \%$ of the U.S. population resided there. Accordingly, for that region, residential construction is a much better surrogate for commercial construction than is population, so we used the proportion of residential construction in each state of that region to represent the proportion of commercial construction that took place there. In contrast, the Pacific division accounted for $16.4 \%$ of total national commercial construction and is home to $16.0 \%$ of the U.S. population, but it only accounted for $13.2 \%$ of U.S. residential construction. Accordingly, for each state in that region, we used its share of the national population as a surrogate for the proportion of commercial construction occurring there.

\section{RATING AND LABELING}

\section{Metric: Types of energy-consuming devices for which energy-efficiency rating and labeling systems were endorsed by the state}

The energy-savings coefficients in this project area describe the amount of energy saved - statewide - as a result of a state's endorsement of rating and labeling systems for up to 15 different types of energy-consuming devices. Because the ENERGY STAR program is the biggest and most successful rating and labeling program operating at this time and many states use SEP funds to encourage participation in the ENERGY STAR program, we used the savings associated with the ENERGY STAR program to represent the savings achieved by all state rating and labeling efforts.

We began by establishing a set of 15 widely-used energy-consuming devices and identifying the difference in annual energy use between an ENERGY STAR unit and a typical unit for each type of device (Webber, Brown, and Koomey 2000). Then, we multiplied the number of ENERGY STAR units sold annually for each of the 15 devices (nationwide) by the 
unit-savings for each device to get annual national savings for each one. The national savings for each type of energy-consuming device was adjusted downward by multiplying by an "attribution factor" of 0.10, which approximates the proportion of ENERGY STAR purchases made as a result of state encouragement (Feldman and Tannenbaum 2000). The savings for each type of device and the numbers used in their calculation are shown in Table A.2.

For each state, per-unit energy savings for each type of device were estimated by multiplying the nationwide savings number by that state's own unique Energy Star sales coefficient. Each state's coefficient represents the percentage of nationwide sales of major Energy Star appliances that occurred in that state (D \& R International 2004).

Table A.2. Estimated energy savings from rating and labeling

\begin{tabular}{lcccc}
\hline & $\begin{array}{l}\text { Energy Star } \\
\text { savings per } \\
\text { unit (million } \\
\text { source BTUs) }\end{array}$ & $\begin{array}{l}\text { Number of } \\
\text { Energy Star } \\
\text { units sold in } \\
\text { U.S., 2002 }\end{array}$ & $\begin{array}{l}\text { National } \\
\text { savings, 2002 } \\
\text { (million source } \\
\text { BTUs) }\end{array}$ & $\begin{array}{l}\text { Adjusted national } \\
\text { savings (using } \\
\text { 0.10 “attribution } \\
\text { factors” (million } \\
\text { source BTUs) }\end{array}$ \\
Device & & & & \\
Office Computer/Monitor & 2.938 & $22,941,000$ & $67,400,658$ & $6,740,066$ \\
Hope Computer/Monitor & 0.853 & $11,402,000$ & $9,725,906$ & 972,591 \\
Fax Machine & 1.801 & $2,271,000$ & $4,090,071$ & 409,007 \\
Copier & 3.033 & 209,000 & 633,897 & 63,390 \\
Multi-function Device & 6.540 & $1,338,000$ & $8,750,520$ & 875,052 \\
Scanner & 2.654 & $6,810,000$ & $18,073,740$ & $1,807,374$ \\
Printer & 2.085 & $7,369,000$ & $15,364,365$ & $1,536,437$ \\
TV & 0.360 & $10,446,000$ & $3,760,560$ & 376,056 \\
VCR & 0.171 & $12,028,000$ & $2,056,788$ & 205,679 \\
TV/VCR & 0.332 & $4,643,000$ & $1,541,476$ & 154,148 \\
Audio Equipment & 0.171 & $3,687,000$ & 630,477 & 63,048 \\
Room AC & 0.663 & $2,195,000$ & $1,455,285$ & 145,529 \\
Dishwasher & 0.569 & $2,262,000$ & $1,287,078$ & 128,708 \\
Refrigerator & 1.137 & $1,956,000$ & $2,223,972$ & 222,397 \\
Clothes Washer & 2.464 & $1,224,000$ & $3,015,936$ & 301,594 \\
\hline
\end{tabular}

\section{HOME ENERGY RATING SYSTEMS (HERS) AND ENERGY-EFFICIENCY MORTGAGES (EEMs)}

\section{Metric: Number of energy-efficiency mortgages issued}

Information was taken from a study by Louisiana's Department of Natural Resources of its proposed Energy Rated Homes of Louisiana Program (Applied Technology Research Corporation 1995). Their study offered several scenarios composed of different energy-savings percentages, all based on a 5\% market penetration assumption for the energy-efficiency mortgage. The savings assumptions were 20,30 and 40 percent. We used the 20 percent savings assumption as being the most reasonable. This savings level yielded an estimate of 37.6 million source BTUs per house. An alternative estimate (Residential Energy Services Network 2001) was available, but that estimate of 70.625 million source BTUs per house was nearly equivalent to the 40 percent savings scenario of the Louisiana study. Accordingly, we chose to use the coefficient of 37.6 million source BTUs savings per house. 


\section{FINANCIAL INCENTIVES}

\section{Metric: Monetary value of rebates provided, by sector}

We were able to find defensible study results on rebate payments and the associated energy savings for the following four programs:

- Anaheim Public Utilities Energy Efficiency Incentives Program: covers residential, commercial, industrial, and institutional sectors. Estimated annual energy savings were 0.0191 million source BTUs per dollar of rebate provided in the residential sector and 0.1661 million source BTUs per dollar of rebate in the commercial, industrial, and institutional sectors combined (City of Anaheim 1998).

- Pacific Gas and Electric (PG\&E) Single Family Home Energy Efficiency Rebate Program: as the name implies, this program provides rebates on energy-efficiency products for single family dwellings. Estimated annual energy savings were 0.0272 million source BTUs per dollar of rebate provided (PG\&E 2003a; PG\&E 2004a). This is relatively close to the amount of residential sector savings reported by the Anaheim program.

- Pacific Gas and Electric Multifamily Energy Efficiency Rebate Program: this program provides rebates for qualified energy-efficiency improvements in apartment units and the common areas of apartments, condominium complexes, and mobile home parks. Estimated annual energy savings were 0.0380 million source BTUs per dollar of rebate (PG\&E 2003b; PG\&E 2004b).

- Pacific Gas and Electric Express Efficiency Program: provides equipment rebates for the commercial, industrial, institutional, and agricultural sectors. Estimated annual energy savings were 0.1455 million source BTUs per dollar of rebate (PG\&E 2001). This figure is very similar to the savings reported for the non-residential sectors by the Anaheim program.

\section{Residential}

Simple average of the Anaheim, PG\&E Single Family, and PG\&E Multifamily programs: 0.0281 million source BTUs per dollar of rebate.

\section{Commercial}

Simple average of the Anaheim and PG\&E Express Efficiency programs: 0.1558 million source BTUs per dollar of rebate.

\section{Industrial}

Simple average of the Anaheim and PG\&E Express Efficiency programs: 0.1558 million source BTUs per dollar of rebate.

\section{Institutional}

Simple average of the Anaheim and PG\&E Express Efficiency programs: 0.1558 million source BTUs per dollar of rebate. 


\section{Agricultural}

This multiplier was taken from the PG\&E Express Efficiency program, which is the only one that addressed measures taken in the agricultural sector. The savings found in this study were 0.1455 million source BTUs per dollar of rebate.

\section{INTEREST REDUCTION PROGRAMS}

\section{Metric: Monetary value of interest reductions provided, by sector}

We were able to locate only one study showing the energy savings associated with an interest reduction program. The program in question is the Loan Fund supported by New York state under its New York Energy \$mart Program (New York State Energy Research and Development Authority 2001a; New York State Energy Research and Development Authority 2003). Dividing energy savings by the funds provided (using information from an early status report issued in 2001 and a follow-up report done two years later) yields an energy-savings coefficient of 0.0423 million source BTUs per dollar of interest reduction. This program covers residential, commercial, industrial, institutional, and agricultural measures, so the same coefficient was used for all of those sectors.

\section{ALTERNATIVE ENERGY}

\section{Metric: Number of alternative fuel vehicles purchased by state and local government agencies}

We considered three types of alternative fuel vehicles (AFVs): those using liquefied petroleum gas (LPG), those powered by compressed natural gas (CNG), and those fueled by a gasoline-ethanol mix that is $85 \%$ ethanol (E-85). In 2001, these vehicles accounted for slightly more than $94 \%$ of AFVs in the United States (EIA 2002b). Of all AFVs of these three types, $60 \%$ used LPG, 25\% used CNG, and 15\% used E-85. We assumed that the miles driven per year for a conventional vehicle and these three AFVs would be the same: 11,435 miles, which is the weighted average number of miles driven by passenger cars and light trucks (U.S. DOE, 2003d), assuming the same mix of cars (47.1\%) and trucks (52.9\%) described in the Procurement section. Based on this mix, we calculated a weighted average fuel efficiency of 19.7 miles per gallon for a conventional vehicle. The assumption that AFVs are driven approximately the same distance annually as conventional vehicles is supported by two studies of alternative fuel vehicles in government fleets (Whalen and Coburn 1997; Whalen and Coburn 1999).

We decided to measure this metric in terms of barrels of oil saved because the use of alternative fuel vehicles is more of a fuel-switching than a fuel-saving program. Our methodology was to compute gasoline (or gasoline-equivalent) savings for each type of vehicle and compute an average savings for all three vehicles. Then, this average savings number was converted into barrels of oil savings per AFV. 
We assumed that all fuel used by CNGs would count toward saving oil because CNG is not a petroleum-based fuel. Therefore, one CNG vehicle would save 11,435 (miles driven per year) divided by 19.7 (miles per gallon), or 580 gallons of gasoline.

We assumed that $85 \%$ of the fuel used by E- 85 s should be counted as gasoline savings. Because such a vehicle averages 14.7 miles per gallon (U.S. DOE and EPA 2004) and we are assuming it is driven 11,435 miles per year, it uses 778 gallons of E-85, 15\% (117 gallons) of which is gasoline. So savings amount to 463 gallons of gasoline (580 minus 117).

For LPG vehicles, we calculated savings based on the widely-accepted estimate that roughly half of the LPG used in this country comes from oil and the other half comes from natural gas. Accordingly, half of the fuel consumed by LPG vehicles is a petroleum product and should not be counted as savings. A typical LPG vehicle averages 12.8 miles per gallon (U.S. DOE and EPA 2004) so it would use 893 gallons of fuel to travel 11,435 miles, half of which (447 gallons) is a petroleum product. This compares to consumption of 580 gallons of gasoline by a conventional vehicle, yielding a savings of 133 gallons of petroleum-based fuel (580 minus 447).

Averaging the above estimates based on the percentage of the different kinds of vehicles in use yields a gasoline savings of approximately 294 gallons per AFV. Assuming 42 gallons of gasoline per barrel of oil yields our energy-savings coefficient of 7 barrels of oil saved per AFV.

\section{Metric: Number of conventional vehicles converted by state and local government agencies to allow alternative fuel use} (see above).

The energy-savings coefficient for this metric is the same as for AFV vehicles purchased

\section{Metric: Number of hybrid vehicles purchased by state and local government agencies}

Purchase of hybrid vehicles can result in significant fuel savings. It is known that the average conventional automobile has a fuel efficiency of 22.1 miles per gallon combined for city and highway driving (U.S. DOE 2003d). We chose as our hybrid vehicle the Toyota Prius, whose fuel efficiency rating is $60 \mathrm{MPG}$ for city driving and $51 \mathrm{MPG}$ for highway driving (http://www.fueleconomy.gov). We assumed that 55\% of vehicle-miles traveled are in the city and $45 \%$ are on the highway. Thus, average MPG for our hybrid is 56 . We used the Transportation Energy Data Book's figures of 11,766 miles driven per year for the average automobile. Based on these numbers, we calculated that an average conventional vehicle would consume 532 gallons of gasoline a year whereas the hybrid would consume only 210 gallons per year. The fuel savings is 322 gallons. Assuming one gallon of gasoline is equivalent to 123,905 BTUs, the average saving for a hybrid vehicle is 39.9 million BTUs annually.

\section{Metric: Number of private sector refueling stations for alternative fuel vehicles}

Our goal here is to estimate the number of barrels of oil saved that are attributable to a single private refueling station. We assumed that AFVs would not be viable without the existence of special refueling stations, so it seems reasonable to give those stations credit for the energy savings achieved by the AFVs they service. From the U.S. DOE's Transportation Energy Data Book (2002c) we were able to calculate the average number of vehicles per station for each of the 
three AFVs addressed above: 79 vehicles per LPG station, 89 vehicles per CNG station, and 312 vehicles per E- 85 station. These numbers were averaged according to the proportion of these vehicles in use to yield an average of $116 \mathrm{AFVs}$ per station. As discussed above, we estimated a savings of 7 barrels of oil per AFV. Multiplying these last two numbers together $(116 \mathrm{x} 7)$ yields our energy-savings coefficient of 812 barrels of oil savings per AFV refueling station.

\section{Metric: Number of megawatts of wind-powered generating capacity installed}

There are 8,760 hours per year. Therefore, a maximum of 8,760 megawatt hours of electricity could be produced for each megawatt of wind-powered generating capacity installed. However, the wind does not blow regularly or consistently every hour of every day. Based on reports in the literature (Lap 2002), we chose a fairly conservative load factor of 0.25 , meaning that on average a wind turbine's output per year would be $25 \%$ of its maximum potential. Thus, we estimate that 2200 megawatt hours of electricity are generated per megawatt of wind-powered generating capacity installed. Converting this site energy estimate to source BTUs (2200 x 10.883 ) produces our multiplier of 23, 943 million source BTUs per megawatt of wind-powered generating capacity installed.

\section{Metric: Number of megawatts of photovoltaic generating capacity installed}

Our approach to photovoltaic (PV) generating capacity is exactly the same as the approach taken with respect to wind. The maximum number of megawatt hours of electricity produced per megawatt of photovoltaic generating capacity installed would be 8,760 . However, the annual output of a PV system depends upon latitude and climate. The literature suggests that output varies between 1,400 and 2,000 megawatt hours per megawatt installed (Green Building Services 2001). We chose a fairly conservative estimate of 1,600 megawatt hours of electricity per megawatt installed. Converting this site energy estimate to million source BTUs $(1600 \mathrm{x}$ 10.883 ) produces our multiplier of 17,413 million source BTUs per megawatt of PV generating capacity installed.

\section{TAX CREDITS}

\section{Metric: Monetary value of tax credits given, by sector}

The Oregon Office of Energy (2000) reported a number of tax credits at various maximum credit levels: 20,613 at the $\$ 1500$ credit level for renewable resources; 42,636 at $\$ 350$ for appliances; 20 at $\$ 1500$ for alternative fuel vehicles $(\$ 750$ for vehicles and $\$ 750$ for a recharging system); and 138 at $\$ 250$ for energy-efficient ducts. Many of the credits given were for less than the maximum value allowed by the state. The total cumulative values of credits given over the life of the program in each category were: $\$ 21,650,542$ for renewables, $\$ 6,267,451$ for appliances, $\$ 27,920$ for alternative fuel vehicles, and $\$ 26,609$ for ducts. The total cost of tax credits is $\$ 27,972,522$. These were estimated to have saved 53.4 million $\mathrm{kWh},(581,152$ million source BTUs), 889,000 therms of natural gas (88,900 million source BTUs), and 11,000 gallons (1,529 million source BTUs) of fuel oil. This amounts to savings of 671,581 million source BTUs in total.

The calculation $(671,581$ million source BTUs/\$27,972,522) yields a coefficient value of 0.024 million source BTUs per dollar. The same coefficient was used in all sectors (residential, 
commercial, industrial, institutional, transportation, and agricultural) because the Oregon program addressed measures relevant to all those sectors.

\section{TRAFFIC SIGNALS AND CONTROLS}

\section{Metric: Number of energy-efficient traffic signals installed}

There is a national effort to replace old traffic signals with light-emitting diode technology. The LEDs produce colored light that does not have to be filtered. Energy savings are on the order of 80-90 percent. A 12-inch LED uses 25 Watts or less, compared to 150 Watts for an incandescent bulb (Consortium for Energy Efficiency 2001). Each LED saves 125 watts during the period that it is producing light, and there are three lights per signal. Based on the available data (McRae and Peters 2003), we assume that the red, green, and yellow lamps are lit $50 \%, 45 \%$, and $5 \%$ of the time, respectively. We further assume that, because green lamps are more expensive than red ones and yellow lamps are lit so infrequently, that the red lamps will be replaced in all installations, the green lamps will be replaced half the time, and the yellow lamps will never be replaced. This yields a total of 6,351 hours of operation by LED lamps in the average traffic light that is serviced. Multiplying 125 watts times 6,351 hours yields a savings per traffic signal of $793.9 \mathrm{kWh}$, which is 8.64 million source BTUs.

\section{Metric: Number of street lane-miles for which synchronized traffic signals are installed}

Traffic control systems manage major arterial traffic light operation to improve the flow of traffic and reduce congestion. Reduction of congestion and stop-and-go traffic saves fuel and reduces emission of pollutants from vehicles. Several steps were involved in estimating energy savings per lane-mile of road included within traffic control systems in a state.

The first step was to estimate the daily vehicle miles traveled (VMTs) per vehicle lane mile over a major arterial. Daily VMTs for twenty large metropolitan areas in the United States were obtained. The average daily VMT was calculated to be 10,935 per lane mile. This represents traffic volume on an average day, factoring in any observed differences between weekdays, weekends, and holidays.

The next step was to estimate energy savings attributable to traffic control systems. Estimates were taken from three studies (Skabardonis 2001; Hetrick and McCollough 1996; Virginia Department of Transportation 2000). These studies suggest that a traffic control system can reduce fuel consumption by an average of $9.3 \%$.

The third step was to estimate average fuel efficiency for the average vehicle that travels through the typical arterial in a typical city. We used an average MPG of 20.4, taken from the Transportation Energy Data Book (U.S. DOE 2003d). We converted gallons of gasoline to BTUs using the conversion factor of 123,905 BTUs per gallon.

Lastly, we combined the factors described above using the following formula to arrive at an estimate for annual energy savings per lane mile in a traffic control system: Daily VMTs per lane mile $\mathrm{x} 365$ days per year $\mathrm{x}$ (1/average MPG) x million BTUs/gallon $\mathrm{x} \%$ fuel savings/lane mile $=10,935 \times 365 \times(1 / 20.4) \times 0.123905 \times 0.093=2,255$ million source BTUs per lane mile per year. 


\section{CARPOOLS AND VANPOOLS}

\section{Metric: Number of new carpools and vanpools formed}

\section{Carpools}

- average size of a carpool (National Center for Transit

Research 2005):

\section{2 persons}

- average length of a single-occupant one-way work trip:

(Transportation Energy Data Book, Edition 23):

12.2 miles

- average length of a carpool one-way work trip (ORNL

estimate):

- average annual number of one-way work trips

(Transportation Energy Data Book, Edition 23):

- average automobile fuel efficiency, (Transportation

Energy Data Book, Edition 23):

- BTU/gallon of gasoline (U.S. DOE 2002b):

123,905

- average carpool energy savings:

15 miles

479

$22.1 \mathrm{mpg}$

31.9 million source BTUs

Annual energy use for a single occupant was calculated by: (1) multiplying the one-way single-occupant mileage shown above by the average annual number of one-way work trips; (2) dividing that number by the average number of miles per gallon; and (3) multiplying that by the number of BTUs in a gallon of gasoline. These calculations yield an average energy use of 32.8 million source BTUs for a single occupant work trip. Annual energy use by a carpool was calculated in the same way, using all the same numbers except the average length of a work trip, which is longer for carpools because of the need to pick up extra passengers. These calculations show that annual average energy use by a carpool is 40.3 million source BTUs. To calculate the amount of energy saved by a carpool, single-occupant energy use (32.8 million source BTUs) was multiplied by 2.2 (the number of occupants in an average carpool) to show the amount of energy (72.2 million source BTUs) that would be used by carpool occupants if they were driving to work alone. Then, the average carpool energy consumption was subtracted from that number to yield average annual savings of 31.9 million source BTUs (72.2 minus 40.3).

\section{Vanpools}

- average size of a vanpool (U.S. EPA 2002b):

- average length of a single-occupant one-way work trip

(Transportation Energy Data Book, Edition 23):

- average length of a vanpool one-way work trip (ORNL estimate):

- average annual number of one-way work trips

(Transportation Energy Data Book, Edition 23):

- average automobile fuel efficiency, (Transportation

Energy Data Book, Edition 23):

- average van fuel efficiency, (www.fueleconomy.gov):

- BTU/gallon of gasoline (U.S. DOE 2002b):

- average vanpool energy saving:
6 persons

12.2 miles

18 miles

479

$22.1 \mathrm{mpg}$

$17.3 \mathrm{mpg}$

123,905

135.0 million source BTUs 
Annual energy use for a single occupant was calculated in the manner described above under Carpools, showing an average annual energy use of 32.8 million source BTUs. Annual energy use by a vanpool was calculated in an identical manner, except that the average length of a work trip is longer than for single occupants and for carpools because of the extra passengers involved and the average fuel efficiency is lower because of the larger vehicle required. The calculations show that annual average energy use by a vanpool is 61.8 million source BTUs. To calculate the amount of energy saved by a vanpool, single-occupant energy use was multiplied by 6 (the number of occupants in an average vanpool) to show the amount of energy (196.8 million source BTUs) that would be used by vanpool occupants if they were driving to work alone. Then, the average vanpool energy consumption was subtracted from that number to yield average annual savings of 135.0 million source BTUs (196.8 minus 61.8).

Our coefficient value for carpool and vanpool programs is an unweighted average of the two savings values reported above: 83.5 million source BTUs. 


\section{APPENDIX B. METHOD FOR CALCULATING EMISSIONS REDUCTIONS}

The following steps were taken to calculate emissions reductions for those project areas for which energy savings could be quantified:

1. Obtained data on the average amount of emissions of six different types (Carbon, $\mathrm{NO}_{\mathrm{x}}, \mathrm{SO}_{2}$, VOCs, CO, and PM10) associated with consumption of five different fuel types (electricity, natural gas, fuel oil, coal, and gasoline) from the GPRA Data Call 2003 (U.S. DOE 2001b).

2. Converted emissions from the units given in the GPRA Data Call 2003 (usually, metric tons per trillion source BTUs) to metric tons per million source BTUs. The resulting emissions coefficients are shown in Table B.1.

3. Obtained estimates of the fuel mix for each energy-consuming sector (e.g., residential, commercial) and major activity area from the Energy Information Administration's Annual Energy Review 2002, 1999 CBECS, and from the U.S. Agriculture and Energy Greenhouse Gas Inventory, 1990 - 2001. The fuel mix for each sector or major activity is shown in Table B.2.

4. For each energy-consuming sector and major activity area, calculated coefficients for weighted average emissions per million source BTUs for each type of emission. This was done by multiplying the portion of total fuel usage accounted for by each fuel by the number of metric tons of emissions per million BTUs for that fuel and summing the products for all fuels involved. This was done separately for each of the six emissions types. Table B.3 shows all the emissions coefficients for the various energy use sectors and activity areas.

5. For each project area addressed by a given state, multiplied the weighted average of emissions per million source BTUs for each energy-consuming sector by the estimated number of millions of source BTUs saved in that sector. Then the emissions reductions for all relevant sectors were summed to get the state's total emissions for the project area. Separate calculations were conducted for each of the six emissions types.

6. For each project area, summed the emissions reductions for all responding states to get total reductions for all states combined. Six different sets of calculations were performed to yield emissions reductions for all of the emissions types studied. 
Table B.1. Emissions from each major fuel type, in metric tons per million source BTUs

\begin{tabular}{lcclllll}
\hline Fuel Type & Carbon & $\begin{array}{l}\text { Sulphur } \\
\text { Dioxide } \\
\left(\mathbf{S O}_{\mathbf{2}}\right)\end{array}$ & $\begin{array}{l}\text { Nitrogen } \\
\text { Oxide } \\
\left(\mathbf{N O}_{\mathbf{x}}\right)\end{array}$ & $\begin{array}{l}\text { Carbon } \\
\text { Monoxide } \\
\mathbf{( C O )}\end{array}$ & $\begin{array}{l}\text { Fine } \\
\text { Particulate } \\
\text { Matter } \\
\text { (PM1O) }\end{array}$ & $\begin{array}{l}\text { Volatile } \\
\text { Organic } \\
\text { Compounds } \\
\text { (VOCs) }\end{array}$ \\
\hline Electricity & 0.01783 & 0.000196 & 0.000146 & 0.000023 & 0.000004 & 0.000003 \\
Natural Gas & 0.0144 & 0 & 0.000106 & 0.000029 & 0 & 0.000003 \\
Oil & 0.01975 & 0.000527 & 0.00014 & 0.000013 & 0.000007 & 0.000004 \\
Coal & 0.02574 & 0.000568 & 0.000254 & 0.000011 & 0.000012 & 0.000001 \\
Gasoline & 0.01917 & - & - & - & - & - & - \\
Diesel Fuel & 0.01917 & - & - & - & - & - & - \\
\hline
\end{tabular}


Table B.2. Fuel mix for key energy use sectors or activities

\begin{tabular}{|c|c|c|c|c|c|c|}
\hline $\begin{array}{l}\text { Energy Use Sector or } \\
\text { Activity }\end{array}$ & $\begin{array}{l}\text { Electricity } \\
\text { as } \\
\text { proportion } \\
\text { of total } \\
\text { energy use } \\
\end{array}$ & $\begin{array}{l}\text { Natural gas as } \\
\text { proportion of } \\
\text { total energy } \\
\text { use }\end{array}$ & $\begin{array}{l}\text { Oil as } \\
\text { proportion } \\
\text { of total } \\
\text { energy use }\end{array}$ & $\begin{array}{l}\text { Coal as } \\
\text { proportion } \\
\text { of total } \\
\text { energy use }\end{array}$ & $\begin{array}{l}\text { Gasoline as } \\
\text { proportion } \\
\text { of total } \\
\text { energy use } \\
\end{array}$ & $\begin{array}{l}\text { Diesel fuel } \\
\text { as } \\
\text { proportion } \\
\text { of total } \\
\text { energy use } \\
\end{array}$ \\
\hline Residential & 0.6789 & 0.2465 & 0.074 & 0.0006 & 0 & 0 \\
\hline Commercial & 0.7672 & 0.1852 & 0.042 & 0.0056 & 0 & 0 \\
\hline Industrial & 0.3548 & 0.2752 & 0.3 & 0.07 & 0 & 0 \\
\hline Institutional & 0.8318 & 0.1467 & 0.0215 & 0 & 0 & 0 \\
\hline Transportation & 0.00004 & 0.001 & 0.0006 & 0 & 0.7702 & 0.2281 \\
\hline Agricultural & 0.6108 & 0.0471 & 0.0171 & 0 & 0.0745 & 0.2505 \\
\hline School Education & 0.6789 & 0.2465 & 0.074 & 0.0006 & 0 & 0 \\
\hline School & 0.7386 & 0.2158 & 0.0456 & 0 & 0 & 0 \\
\hline Health Care & 0.7481 & 0.2316 & 0.0203 & 0 & 0 & 0 \\
\hline Government & 0.8836 & 0.102 & 0.0144 & 0 & 0 & 0 \\
\hline Vehicles & 0 & 0 & 0 & 0 & 1 & 0 \\
\hline Office Equipment & 1 & 0 & 0 & 0 & 0 & 0 \\
\hline HVAC & 0.6931 & 0.276 & 0.0309 & 0 & 0 & 0 \\
\hline Streetlights & 1 & 0 & 0 & 0 & 0 & 0 \\
\hline Exit Signs & 1 & 0 & 0 & 0 & 0 & 0 \\
\hline Electronic equipment & 1 & 0 & 0 & 0 & 0 & 0 \\
\hline Room AC & 1 & 0 & 0 & 0 & 0 & 0 \\
\hline Dishwasher & 0.7495 & 0.227 & 0.0235 & 0 & 0 & 0 \\
\hline Refrigerator & 1 & & & & & \\
\hline Clothes Washer & 0.6431 & 0.3234 & 0.0335 & 0 & 0 & \\
\hline Hybrid vehicles & 0 & 0 & 0 & 0 & 1 & 0 \\
\hline Wind/photovoltaic & 1 & 0 & 0 & 0 & 0 & 0 \\
\hline LED Signals & 1 & 0 & 0 & 0 & 0 & 0 \\
\hline Synchronized Signals & 0.00004 & 0.001 & 0.0006 & 0 & 0.7702 & 0.2281 \\
\hline Carpools/Vanpools & 0 & 0 & 0 & 0 & 1 & 0 \\
\hline
\end{tabular}


Table B.3. Average emissions for key energy use sectors or activities, in metric tons per million source BTUs

\begin{tabular}{|c|c|c|c|c|c|c|}
\hline $\begin{array}{l}\text { Energy Use Sector or } \\
\text { Activity }\end{array}$ & Carbon & $\begin{array}{l}\text { Sulphur } \\
\text { Dioxide } \\
\left(\mathrm{SO}_{2}\right) \\
\end{array}$ & $\begin{array}{l}\text { Nitrogen } \\
\text { Oxide } \\
\text { (NOx) } \\
\end{array}$ & $\begin{array}{l}\text { Carbon } \\
\text { Monoxide } \\
\text { (CO) }\end{array}$ & $\begin{array}{l}\text { Fine } \\
\text { Particulate } \\
\text { Matter } \\
\text { (PM10) } \\
\end{array}$ & $\begin{array}{l}\text { Volatile } \\
\text { Organic } \\
\text { Compounds } \\
\text { (VOCs) } \\
\end{array}$ \\
\hline Residential & 0.01567 & 0.000172 & 0.000136 & 0.000024 & 0.0000032 & 0.000003 \\
\hline Commercial & 0.01732 & 0.000176 & 0.000139 & 0.0000236 & 0.0000034 & 0.000003 \\
\hline Industrial & 0.018016 & 0.000267 & 0.0001408 & 0.000021 & 0.00000436 & 0.0000032 \\
\hline Institutional & 0.01737 & 0.000174 & 0.00014 & 0.0000237 & 0.0000035 & 0.000003 \\
\hline Transportation & 0.019165 & 0.0000003 & 0.0000002 & 0.00000004 & 0.0000000044 & 0.0000000055 \\
\hline Agricultural & 0.018137 & 0.000129 & 0.000097 & 0.0000156 & 0.0000026 & 0.000002 \\
\hline School Education & 0.01567 & 0.000172 & 0.000136 & 0.0000237 & 0.00000324 & 0.0000031 \\
\hline School & 0.017177 & 0.000169 & 0.000137 & 0.0000238 & 0.00000327 & 0.0000031 \\
\hline Health Care & 0.017075 & 0.000157 & 0.0001366 & 0.000024 & 0.000003 & 0.000003 \\
\hline Government & 0.017508 & 0.000181 & 0.000142 & 0.000024 & 0.0000036 & 0.000003 \\
\hline Vehicles & 0.01917 & 0 & 0 & 0 & 0 & 0 \\
\hline Office Equipment & 0.01783 & 0.000196 & 0.000146 & 0.000023 & 0.000004 & 0.000003 \\
\hline HVAC & 0.016943 & 0.000152 & 0.000135 & 0.000024 & 0.000003 & 0.000003 \\
\hline Streetlights & 0.01783 & 0.000196 & 0.000146 & 0.000023 & 0.000004 & 0.000003 \\
\hline Exit Signs & 0.01783 & 0.000196 & 0.000146 & 0.000023 & 0.000004 & 0.000003 \\
\hline Electronic equipment & 0.01783 & 0.000196 & 0.000146 & 0.000023 & 0.000004 & 0.000003 \\
\hline Room AC & 0.01783 & 0.000196 & 0.000146 & 0.000023 & 0.000004 & 0.000003 \\
\hline Dishwasher & 0.017097 & 0.000159 & 0.000137 & 0.000024 & 0.0000032 & 0.000003 \\
\hline Refrigerator & 0.01783 & 0.000196 & 0.000146 & 0.000023 & 0.000004 & 0.000003 \\
\hline Clothes Washer & 0.016785 & 0.000144 & 0.000133 & 0.0000246 & 0.0000028 & 0.000003 \\
\hline Hybrid vehicles & 0.01917 & 0 & 0 & 0 & 0 & 0 \\
\hline Wind/photovoltaic & 0.01783 & 0.000196 & 0.000146 & 0.000023 & 0.000004 & 0.000003 \\
\hline LED Signals & 0.01783 & 0.000196 & 0.000146 & 0.000023 & 0.000004 & 0.000003 \\
\hline Synchronized Signals & 0.019165 & 0.0000003 & 0.0000002 & 0.000000038 & 0.0000000044 & 0.0000000055 \\
\hline Carpools/Vanpools & 0.01917 & 0 & 0 & 0 & 0 & 0 \\
\hline
\end{tabular}




\section{INTERNAL DISTRIBUTION}

1. M. A. Brown

2. W. G. Craddick

3. V. T. D'Urso

4-21. M. T. Eady

22-31. J. F. Eisenberg

32. E. C. Fox

33. M. B. Gettings

34. G. K. Jacobs

35. M. Madgett
36. M. Martin

37-46. M. Schweitzer

47. R. B. Shelton

48-52. B. E. Tonn

53. A. K. Wolfe

54-56. ESD Library

57. ORNL Central Research Library

58. ORNL Laboratory Records - RC

\section{EXTERNAL DISTRIBUTION}

59. Mark L. Bailey, U.S. DOE, EE-2K, Room 5E-080, Office of the Weatherization and Intergovernmental Program, 1000 Independence Avenue, SW, Washington, DC 20585.

60. Sharyn Barata, B \& B Resources, 115 Longwater Cove, Roswell, GA 30075.

61. Daniel T. Beckley, U.S. DOE, EE-2K, Room 5E-098, Office of the Weatherization and Intergovernmental Program, 1000 Independence Avenue, SW, Washington, DC 20585.

62. Darell A. Beschen, Jr., U.S. DOE, EE-3B, Room 6B-038, Office of Planning, Budget and Analysis, 1000 Independence Avenue, SW, Washington, DC 20585.

63. Carole Buncher, 3016 Tilden Street, NW, Suite 103, Washington, DC 20008.

64. Brian E. Card, U.S. DOE, EE-3B, Room 6B-038, Office of Planning, Budget and Analysis, 1000 Independence Avenue, SW, Washington, DC 20585.

65. Debi Conrad, West Virginia Development Office, Building 6, Room 645, State Capitol Complex, Charleston, WV 25305.

66. Jeffrey Dowd, U.S. DOE, EE-3B, Room 6B-038, Office of Planning, Budget and Analysis, 1000 Independence Avenue, SW, Washington, DC 20585.

67. Chantal Fryer, South Carolina Energy Office, 1201 Main Street, Suite 1010, Columbia, SC 29201.

68. Robert W. Garland, U.S. DOE, EE-2K, Room 5E-080, Office of the Weatherization and Intergovernmental Program, 1000 Independence Avenue, SW, Washington, DC 20585.

69. Jeff Genzer, Duncan, Weinberg, Genzer, and Pembroke, 1615 M. Street, NW, Suite 800, Washington, DC 20036.

70. Michael J. Gonzalez, U.S. DOE, EE-3B, Room 5E-098, Office of Planning, Budget and Analysis, 100 Independence Avenue, SW, Washington, DC 20585.

71. Douglas Goodman, U.S. DOE, EE-3B, Room 6B-056, Office of Planning, Budget and Analysis, 1000 Independence Avenue, SW, Washington, DC 20585.

72. Nick Hall, TecMRKT Works, 165 West Netherwood Road, Suite A, Oregon, WI 53575.

73. Tobin K. Harvey, U.S. DOE, EE-1, Room 6A-013, Office of the Assistant Secretary, 1000 Independence Avenue, SW, Washington, DC 20585.

74. Ruth Horton, New York State Energy Research and Development Authority, 17 Columbia Circle, Albany, NY 12203.

75-124. Faith S. Lambert, U.S. DOE, EE-2K, Room 5E-080, Office of the Weatherization and Intergovernmental Program, 1000 Independence Avenue, SW, Washington, DC 20585. 
125. Pierre Landry, Southern California Edison, P.O. Box 800, 2131 Walnut Grove Avenue, MS-B7, $3^{\text {rd }}$ Floor, GO-3, Rosemead, CA 91770.

126. Linda Limback, Minnesota Department of Commerce, $857^{\text {th }}$ Place East, Suite 500, St. Paul, MN 55101.

127. Janet Lockhart, South Carolina Energy Office, 1201 Main Street, Suite 1010, Columbia, SC 29201.

128. Ellen Lutz, U.S. DOE Mid-Atlantic Regional Office, The Wanamaker Building, 100 Penn Square East, Suite 890 South, Philadelphia, PA 19107-3396.

129. Tom Martin, Michigan Department of Labor and Economic Growth, P.O. Box 30221, 611 W. Ottawa, $4^{\text {th }}$ Floor, Lansing, MI 48909.

130. Donald Milsten, State Service Program, 7907 Ivy Lane, Baltimore, MD 21208.

131. Monica Nevius, Consortium for Energy Efficiency, 98 N. Washington Street, Suite 101, Boston, MA 02114.

132. Jane S. Peters, Research Into Action, P.O. Box 12312, Portland, OR 97212.

133. Christine Reinfelds, U.S. DOE, Boston Regional Office, JFK Federal Building, Suite 675, Boston, MA 02203-0002.

134. Robert Sandoli, The Office of Management and Budget, $72517^{\text {th }}$ Street, NW, Suite 8025, Washington, DC 20503.

135. Ronald V. Santoro, U.S. DOE, EE-2K, Room 5E-080, Office of the Weatherization and Intergovernmental Program, 1000 Independence Avenue, SW, Washington, DC 20585.

136-190. Diane Shea, NASEO, 1414 Prince Street, Suite 200, Alexandria, VA 22314.

191. Carolyn Sullivan, Oklahoma Department of Commerce, 900 N. Stiles Avenue, P.O. Box 26980, Oklahoma City, OK 73126-0980.

192. John R. Sullivan, U.S. DOE, EE-30, Room 6A-067, Office of the Deputy Assistant Secretary, 1000 Independence Avenue, SW, Washington, DC 20585.

193. James P. Taylor, New Hampshire Office of Energy and Planning, 57 Regional Drive, Suite 3, Concord, NH 03301.

194. Eric W. Thomas, U.S. DOE, EE-2K, Room 5E-080, Office of the Weatherization and Intergovernmental Program, 1000 Independence Avenue, SW, Washington, DC 20585.

195. Edward Vine, Lawrence Berkeley National Laboratory, One Cyclotron Road, Building 90, Room 4000, Berkeley, CA 94720-8136.

196. Carol White, National Grid USA Service Co., Inc., 55 Bearfoot Road, Northborough, MA 01532-1555.

197. Lisa Yoder, Utah Energy Office, 1594 W. North Temple, Suite 3610, Salt Lake City, UT 84114-6480. 